\title{
Advantages and shortcomings of the utilization of recycled wastes as aggregates in structural concretes
}

\author{
Sérgio Miraldo ${ }^{\mathrm{a}, *}$, Sérgio Lopes ${ }^{\mathrm{a}}$, Fernando Pacheco-Torgal ${ }^{\mathrm{b}}$, Adelino Lopes ${ }^{\mathrm{c}}$ \\ ${ }^{a}$ University of Coimbra, CEMMPRE, Department Mech Engn, P 3030-788 Coimbra, Portugal \\ ${ }^{\mathrm{b}}$ University of Minho, C-TAC Research Centre, Engineering School, Guimarães, Portugal

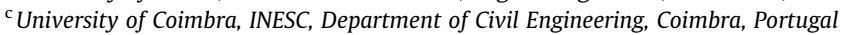

\section{H I G H L I G H T S}

- Comprehensive, systematic review on current state of the art concerning the utilization of a wide array of wastes as aggregates, in ordinary Portland cement concrete compositions, for structural applications.

- Analysis of the advantages and shortcomings for each recycling material in the context of the adoption of circular patterns in the construction sector life cycle.

- Evaluation of alkali-activated binders as an alternative for overcoming important shortcomings of Portland cement-based structural concretes.

\section{A R T I C L E I N F O}

\section{Article history:}

Received 21 October 2020

Received in revised form 18 March 2021

Accepted 22 May 2021

\section{Keywords:}

Alkali-activated concrete

Recycled aggregates

Waste recycling

Construction and demolition waste

\begin{abstract}
A B S T R A C T
Global material resources are quickly being drained by the demands of global economic development. Simultaneously, the environmental impacts of the massive amounts of waste generated globally every year are also growing exponentially. As such, the implementation of waste recycling through its utilization as a component of a construction material, particularly one with a global demand as high as concrete, is a strategy which acts in both planes: material efficiency and waste generation. This paper details the results of a systematic review performed on the scientific literature that concerns the possibility of incorporating recycled wastes as aggregates in structural ordinary Portland cement concretes. The available literature suggests that a reduced number of wastes of recycled origin may, albeit in low quantities, be used in structural OPC concretes. Furthermore, the presence of substances such as glass wastes or alkali-rich cement fragments in recycled aggregates elevates the potential for expansions originated by the occurrence, in these concretes, of the well known phenomenon known as alkali-silica reaction. Moreover, the variety, quantity and the limits to the utilization of these wastes as aggregates in structural concretes all suggest that a massification of the utilization of recycled aggregates in OPC concretes will not take place. The investigation also found that, in light of the evidence showing that the performance of alkali-activated binder concretes is less impacted by the shortcomings of recycled aggregates, recycled wastes may be better suited for reutilization as aggregates in these concrete compositions.
\end{abstract}

(c) 2021 Elsevier Ltd. All rights reserved.

\section{Introduction}

There has likely never been a time in human history when the demand for material resources was so elevated. In fact, as mentioned in [1], the global demand for engineering materials had, in a fifty-year window and up to the year 2006, already quadrupled. The impending exhaustion of Earth's resources is not a new prospect as, almost 50 years ago, a group of scientists, using a system

\footnotetext{
* Corresponding author.

E-mail address: miraldo@student.uc.pt (S. Miraldo).
}

dynamics computer model to simulate the interactions between population, food production, industrial production, pollution, and consumption of non-renewable natural resources already predicted this outcome for the 21st century [2]. Furthermore, an update to this study performed more than thirty years after the initial document [3], concluded that the original research effort had been nothing more than a waste of time and that Humanity had done very little to avoid the collapse of the Planet's environment.

One of the human activities currently straining the supply of natural resources is the construction industry. As such, it is imperative that, in order to keep growing, this sector implements the 
reduction of the environmental impacts associated with its activities. The urgency of these measures was already stated in the European Comission's communication from 2011 [4] in which, as [5] observed, several milestones regarding the recycling policies of member-states are set for the year 2030, namely, "recycling 65\% of municipal waste, $75 \%$ of packaging waste, and reduce landfill to a maximum of $10 \%$ of municipal waste". In the mentioned EU initiative it is also stated that, the move towards a circular economy, in which systems reuse and recycle resources while also conserving energy, instead of the utilization of open productive systems, where resources are extracted, used to make products and become waste after the product is consumed [6] is inevitable. Therefore, as stated in [7], the adoption of circular patterns in all stages of the construction sector life-cycle, namely trough the consideration of environmental and socioeconomic impacts related to these activities will be necessary. These authors also highlight that the cultural, economical and legislative barriers currently facing the mass utilization of recycled aggregates and that the consideration of a wider analytical framework to this issue must be implemented.

In response to remark 3 . of Reviewer $n^{\circ} 3$ : In the present document, our target for the recycling of the waste, independently of its source, is its potential for use as replacement of natural aggregates in the construction sector, more specifically, in structural concretes. The utilization of natural aggregates in concrete mixtures is one of the most important examples of the depletion of natural resources promoted by the construction sector, as such, this activity naturally becomes a primordial medium for the re-utilization of wastes. The topic of replacing natural aggregates for recycled wastes has attracted substantial scientific research interest in recent years and, as this work demonstrates, considerable progress has been achieved regarding the knowledge of the behavior of these materials.

What follows is the detailed review of the existing literature concerning recycled wastes with potential to replace natural aggregates in concrete compositions for structural applications (Fig. 1). Besides reviewing the available alternatives, this document highlights the limitations of the practical application of these wastes as aggregates in OPC concretes and suggests alternatives recycling pathways for these materials. The materials reviewed were grouped in seven major groups. The first section explores the wastes generated by the mining and quarrying industry, the second details the by-products of energy generation, the third, fourth and fifth concern the wastes involved in the production of basic materials, the seventh is related to domestic and municipal waste, and the last verses the wastes generated by the construction and demolition activities.

\section{Mining and quarrying industry wastes}

The mining and quarrying sector generates large amounts of mineral waste every year. In the European Union alone, and according to Eurostat, mining and quarrying waste represented a $27.6 \%$ share of the total waste generated in the 27 countries of the Union [8]. This industry, is therefore, a prime target for waste recycling as a form of aggregates in concrete as long as the environmental, mechanical and durability performance of the concretes containing these aggregates is adequate. The section focusing on mineral wastes generated by the mining and quarrying sector is divided into two major groups, one dedicated to the by-products of the extraction of a valuable material from an ore, and another which concerns the wastes originated by the processing of the extracted material into the final commercial product.

\subsection{Extractive procedures}

A large share of the mining mineral waste is generated by metallic ore deposits, phosphate ores, coal seams, oil shales and mineral sands. As it happens, the extracted minerals may be rich in sulfides, which, when exposed to the atmosphere or oxygenated ground water, oxidate and produce acid water heavy metals and metalloids. As a consequence, special care needs to be taken when deciding the addition of these wastes to concrete compositions.

\subsubsection{Gold mining waste}

One of the mining wastes that is starting to attract research efforts for potential use as natural aggregate substitution is gold mining waste rock (GR). Although the statistics for the yearly worldwide generation of this wastes are not available,[9], citing a 2001 publication from the South African Department of Water Affairs and Forestry [10], mentions that the amount of gold mining waste generated in the respective country was of 221 million tons (or $47 \%$ of the country's total mineral waste). As this waste is sourced from a rock, in a similar fashion to natural crushed aggregates, its physical properties tend to resemble those of the said natural aggregates. However, while [11,12] found this to be true for the physical and geometrical properties of the coarse fraction (except for abrasion resistance, which is lower for GR), the same cannot be stated when addressing the finer fraction of the aggregates.

In fact, when compared to natural aggregates these wastes were found to possess up to ten fold higher fines content $(<80 \mu \mathrm{m})$ and double the water absorption and abrasion values. When it comes to the chemical composition of GR, the may contain the undesirable presence of pyrite, pyrrhotite and chalcopyrite, as well as a residual amount of several metals and metalloids (making this waste unfit for residential structures concretes). Also, when these materials are present in concrete compositions, the aforementioned physical properties impact the workability of the samples. Microscopy analysis performed by the aforementioned authors shows that pyrite grains with a size under $100 \mu \mathrm{m}$ are significantly more likely to be present in the liberated form (and consequently produce acidity by oxidation) than larger particles. Nevertheless, a large percentage of pyrite grains, as can be seen in Fig. 2, were found to be coated by a Fe oxide rim and therefore, not liberated. The same study found that a total sulfur content of $0.471 \%$ in weight, with its presence mainly located at the $0 \mu \mathrm{m}$ to $5 \mu \mathrm{m}$ range. However, the authors found that the neutralizing presence of calcite and dolomite was also observed and the waste was able to be classified, according to the local (Quebec) legislation, as nonacid generating. Furthermore, TCLP tests showed the nonleachable and non-hazardous nature of GR and one year compressive strength testing revealed that the waste addition leads to a slight strength reduction for coarser fraction replacement, which may be worsened by the addition of the finer fractions of the gold.

\subsubsection{Kaolin mining waste}

Kaolin tailing sand (KTS) is a material that originates from kaolin clays exploration and its recycling potential as aggregate shares many similarities with gold mining waste. Furthermore, in 2012, it was estimated kaolin tailings originating from the production of porcelain raw materials, in China amounted to $2.1 \times 10^{10} \mathrm{t}$ [13]. [14] studied concrete and mortar mixtures in which the fine aggregates were either partially or completely replaced by KTS (obtained through sieving the quartz sand particles from the kaolin clay fraction of the waste). Moreover, either class F fly ash or ground granulated blast furnace slag were used as mineral admixtures and a polycarboxylate SP was added during the mixing operations. The 

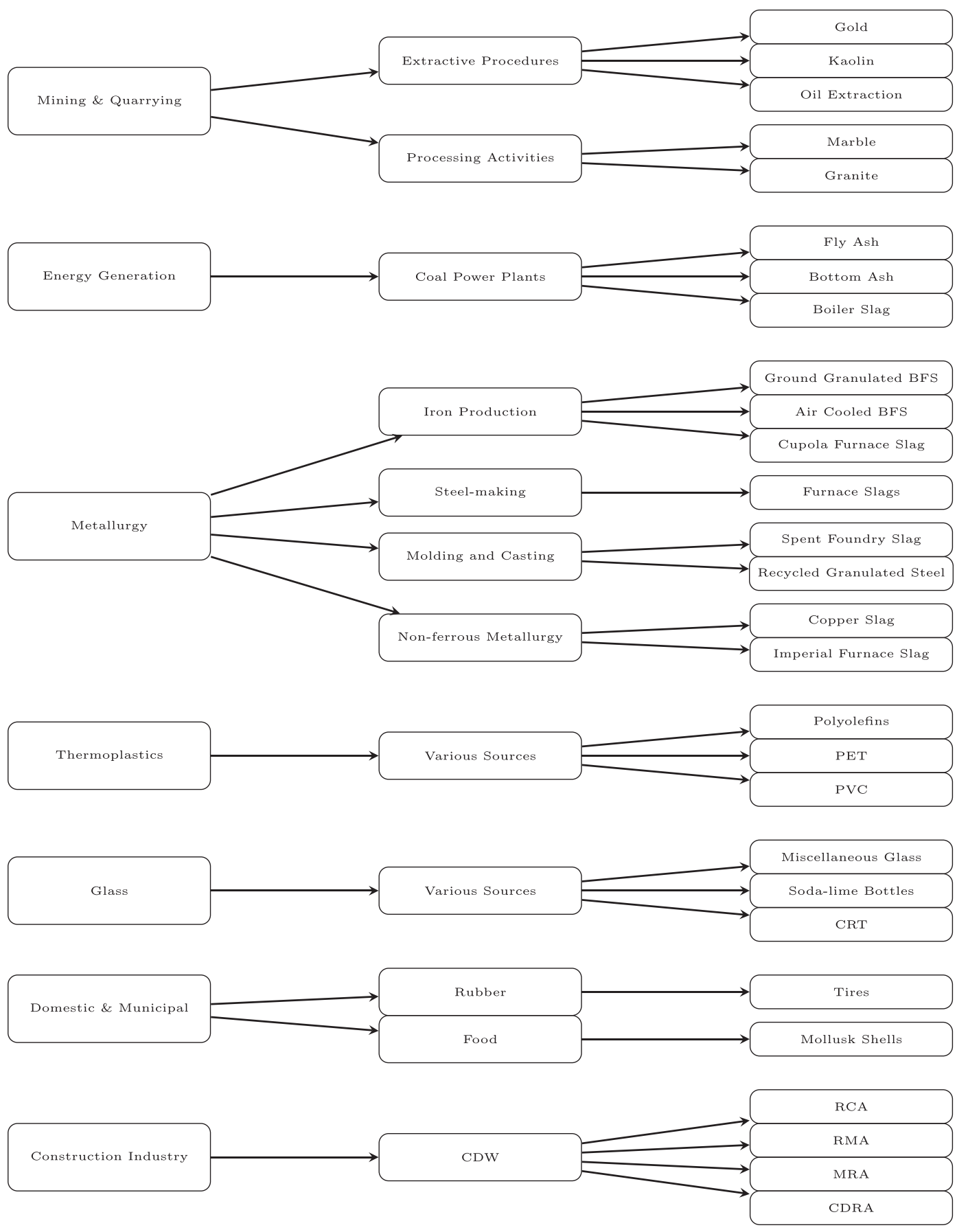

Fig. 1. Summary of wastes with potential for use in structural concretes.

authors found that, compared to natural river sand, KTS possesses higher apparent and bulk density, crushing index (lower hardness) and water absorption, and also, lower sulfate, clay and clay lump content. Microscopy observation also detected higher flat to elongated particle ratio, higher angularity, lower roundness and higher surface roughness. Additionally, mineralogical analysis showed the presence of potassium calcium sulfate and chemical tests revealed the presence of heavy metals (at a rate situated below the maximum established by Chinese regulations). As a consequence of the described aggregate properties, concrete mixtures containing KTS displayed lower workability. Furthermore, accelerated mortar bar expansion tests demonstrated that a $20 \%$ sand replacement rate does not originate meaningful expansions and the waste may therefore be regarded as non-reactive (which my be an important indicator of the low alkali-silica reactivity originated by KTS presence). Moreover, the study shows that, at a $60 \%$ fine aggregate substitution rate, compressive and splitting tensile strength is (at least) not impacted by the addition of the KTS. Finally, rapid chloride ion penetration tests yielded levels of chloride permeability identical to the low permeability reference concretes. In short, although KTS demonstrates low potential as fine aggregate material, as the existing research, which is still scarce, does not support the idea of a meaningful aggregate substitution rate, mainly due to the physical properties of the aggregates.

It is, however, important to highlight that there is a scarcity of relevant studies on the matter of mining wastes potentially pos- 


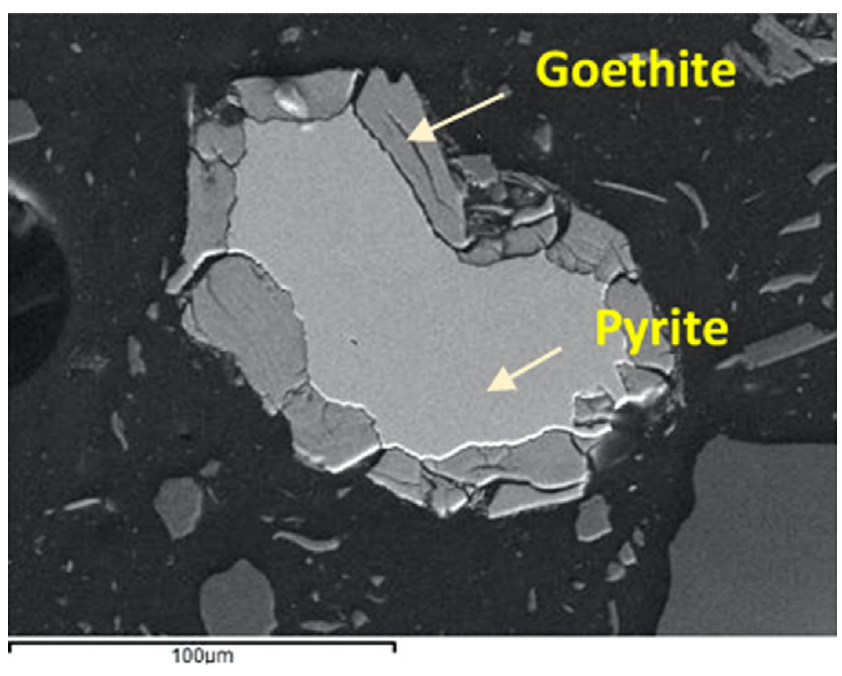

Fig. 2. SEM image of a concrete sample showing a Pyrite grain completely enclosed in Goethite particles [11].

sessing high sulfides content. One such example is the replacement of natural aggregates for iron ore tailings (IOT) in concrete mixtures. In their studies, [15] focused on the geotechnical properties of abandoned Moroccan IOT and found that the most relevant challenge of these materials is the inherent variability of their properties. Nevertheless, the authors found that the waste possessed similar grain size distribution to that of natural aggregates. Furthermore, IOT samples also demonstrated low sulfide content and sulfate release. The results from the acid-generating potential of the wastes was, nevertheless, found to be variable according to the origin of the waste, as IOT from one of the waste sites could be classified as non-acid generating, while material obtained from the other source could only be defined as uncertain as to its acid generating potential. Moreover, the study also found that the tailings may produce high concentrations of lead leachates, although it is stated that the leachates' $\mathrm{pH}$ remained near neutral during the weathering cell tests duration, and that the production of solidified materials could, according to the TCLP tests performed to render mortars in a previous study [16], guarantee the immobilization of the harmful elements (although several properties of these compositions, such as increased porosity, lower CSH and portlandite content are worse than when solely using natural aggregates). Meanwhile, [17] studied the potential for the use of IOT in ultra high performance concrete and found that a $40 \%$ replacement of sand for IOT, together with a 2-day steaming curing period and the use a polycarboxylate-based superplasticiser, resulted in concrete with identical mechanical properties to the reference concrete. Moreover, while the ITZ analysis of the revealed a dense microstructure of these compositions, the authors stress that the presence of oriented crystalline calcium hydroxide around tailing particles may lead to further cracking under loading.

Finally, it is important to mention a recent study [18] concerning the full replacement of coarse natural aggregates for flint from phosphate mine waste rocks in concrete compositions. In terms of the presence of contaminants, flint from phosphate waste rocks does not present the same environmental threat as the mining wastes discussed above and may constitute a viable alternative for concrete aggregates (although the deposits of raw tailings may contain the presence of heavy metals). Moreover, the mixtures were designed in order to attempt to attain the same strength and workability class. For this purpose, and due to higher water absorption of the waste aggregates, the water and superplasticizer content of the mixtures were adjusted accordingly. Nevertheless, the achieved workability of the waste concrete was observed to be significantly inferior to the one displayed by the reference concrete (which can, in turn, influence the analysis of the concrete's strength results). As to the remaining physical and mechanical properties of the waste, no significant difference to the natural counterparts were found. Furthermore, the 28-day compressive strength results of the waste concrete yielded a $16 \%$ reduction in strength when compared to the reference sample(to $29 \mathrm{MPa}$ ), a $9 \%$ increase (to $4.9 \mathrm{MPa}$ ) in flexural strength (which the authors attribute to the superior interlocking between the waste particles and the cement paste, and a $3 \%$ increase (to $2.6 \mathrm{MPa}$ ) in splitting tensile strength, both for the same curing age. In short, despite the extreme scarcity of available research on the topic, the waste shows adequate potential for natural aggregate replacement in structural concrete.

\subsubsection{Oil extraction wastes}

Another example of a waste produced by the mining sector is oil-based drilling cuttings pyrolysis residues (ODPR). These cuttings are generated as a by-product of shale gas exploration and are composed of drilled rocks and sand mixed with the oil-based drilling fluid. For the safe disposal of this waste, which [19] argues can amount to $250 \mathrm{~m}^{3}$ per drilled well it is usually necessary to subject it to physical separation processes and, finally, a pyrolysis of the residue, thus creating the material termed ODPR [19]. ODPR as partial replacement of fine aggregates and cement in ordinary Portland cement (OPC) concretes containing a pozzolanic addition (fly-ash) and a water reducing agent. According to the same authors, ODPR is mainly composed of alumina, silica and calcium oxide, and possesses a relatively low heavy metals $(\mathrm{Hg}, \mathrm{As}, \mathrm{Ba}$ and $\mathrm{Zn}$ ) content. Also, the waste was found to be noninflammable, non-reactive and non-corrosive and, as to leaching toxicity and also the presence of toxic substances, the authors found that the ODPR performance can be placed within the limits established by Chinese regulations. Moreover, regarding biotoxicity hazards, the waste was categorized as non-toxic. Furthermore, the activity index tests performed to ODPR compositions suggest that this material has a moderate pozzolanic nature, and thus, may be eligible for classification as mineral admixture. As such, the authors decided to include a simultaneous cement substitution in the design of the mixtures (which, in our view, may skew the results and cloud the workability and compressive strength analysis of the concretes). Nevertheless, the results show that compressive strength is severely impacted by ODPR and, although some environmental performance results are encouraging, nearly everything is still left to investigate as to the use of ODPR as aggregate in concrete.

\subsection{Processing activities}

In mining operations, after extracting raw material from the earth, and in order to turn it into a commercial product, it is then necessary to process the material. These operations often include waste-generating activities such as cutting the rock into the desired shape, such is the case of the waste produced by the cutting of marble blocks. The waste material resulting from these operations is heterogeneous in size and its commercial applications, especially for the coarser fraction of the waste, are limited. One possible solution to this issue is to promote the utilization of the dust deposited in the sedimentation tanks as concrete aggregate, or alternatively, to reduce the coarser fraction of the waste to grain and use it to the same effect.

\subsubsection{Marble wastes}

Amid the studies focusing on the influence of partially replacing natural sand for waste marble powder in concrete compositions, 
[20-23] state that marble dust tends to maintain many of the properties of the original raw material and thus generally possesses adequate physical and chemical properties for use as concrete aggregate. Nevertheless, the fines content was found to be higher [20] and the particle shape to be more angular and elongated than in natural sands [22]. Both mentioned factors are known to negatively influence workability in cementitious compositions and, if mitigating measures are not adopted, this property tends to decrease with the addition of this waste. Furthermore, the studies also show that the effect of a low fine aggregate for marble wastes replacement level, coupled with the simultaneous introduction of a superplasticizer, leads to a concrete with the same compressive and splitting tensile strength and workability of the original concrete. Moreover, [23] report that the abrasion resistance is slightly affected by the aggregate replacement while the elastic modulus of the concretes is only affected when the substitution of basalt or granite sand is implemented (and is otherwise unaltered when marble waste replaces river sand). Furthermore, [20,22] studied the impact of fine marble waste addition to the water absorption (by immersion and capillarity) of concretes. These authors agree that the addition of marble wastes at an optimized rate leads to an upgrade in both properties, thus indicating that an improvement in the pore matrix structure has taken place. Also, the concrete's resistance to chloride ion penetration may show signs of improvement when the waste replaces basalt and granite sand. In relation to the carbonation resistance, [22] did not find a clear relation between the growth in marble wastes content and the concrete's resistance. At the same time, due to what the authors argue is an effect of the raised compactness and improved pore's structure, drying shrinkage was improved by the marble waste addition.

Another possible methodology is to utilize the coarse particles of marble wastes to replace the same fraction of natural aggregates in concrete. The properties of coarse marble aggregates are very similar to those of other natural coarse aggregates and, although the crushing process can also influence the final shape of the particles, the qualities of this waste are highly reflective of those of the original rock. Nevertheless, [24-26] demonstrate that coarse waste marble aggregates possess a lower resistance to abrasion than basalt, granite or limestone aggregates. This fragility can lead to the lower durability of concretes possessing these wastes. Regarding the workability of the concretes, the literature suggests that this property is not negatively influenced by the coarse aggregate replacement and may even be improved by this practice [24,25]. The research, however, is not unanimous in relation to the effects of the aggregate replacement in compressive and splitting tensile strength and definite conclusions cannot be drawn. Additionally, [25] also observed that the elasticity modulus is slightly impacted (more on limestone and basalt and less in granite concretes) by the marble waste addition. As to durability concerns, [24] states that, despite the fact that water absorption by immersion does not appear to display significant changes with the rise in marble content, absorption by capillarity decreased. The authors justify this behavior as being a consequence of the marble aggregates worse adhesion and the resulting increase in the interface zone pores. The mentioned investigation also focused on the carbonation resistance of the concretes and, for all concretes and curing ages, significant changes introduced by the marble wastes were not observed. Finally, the low alumina content of the marble waste and the consequential lack of tricalcium aluminate formation is the reason attributed by the same study to the considerable increase in chloride penetration originated by the marble wastes incorporation.

\subsubsection{Granite wastes}

Similarly to fine marble wastes, fine granite cuttings can also be used as aggregates in concrete. [27,28] observed that this highly fine waste possesses slightly lower specific gravity and higher water absorption than those of natural aggregates. Both studies also agree that, despite the use of superplasticizers, workability is negatively influenced by the addition of the waste. Furthermore, the same authors found that, for low fine aggregate replacement rates (up to $30 \%$ in weight), compressive and flexural strength slightly increase. Also, [27] reports that the concrete's resistance to abrasion and to water flow is upgraded by the incorporation of granite wastes content, while [28] states that a 20\% granite replacement leads to an improved performance in the concrete's permeable voids content, water absorption by capillarity and ultrasonic pulse velocity (Table 1). Lastly, [27] performed SEM and XRD analysis to the concrete compositions in which they concluded that a $30 \%$ replacement level provides an optimized density for the cement-aggregate matrix and a peak at C-S-H gel formation. Nevertheless, it is important to underline that although low rates of aggregate substitution seem to lead to improvements in the mechanical and durability properties of concrete, it would be important to understand the implications of designing concretes containing the waste but which are of the same workability class. These findings are in line with the conclusions previously reached by [29], which studied the replacement of fine natural aggregates for granite waste powder in concrete compositions (in which no use of a water reducing agent was performed) and also found that fine granite waste has a high specific area and rough and angular texture, and consequently, negatively contributes to the workability performance of the concretes. Furthermore, the study had also found that low (up to 15\% in mass) aggregate replacement rates also lead to the improvement in compressive strength of the concrete, although splitting tensile and flexural strength yielded equal to lower results when comparing to reference concretes. Moreover, UPV, chloride penetration and carbon penetration depth values for the same compositions (containing up to $15 \%$ replacement of aggregates) were also unaffected by the presence of the waste, while chloride penetration rate and water permeability were, contrary to the findings contained in the more recent studies mentioned, negatively impacted by the presence of granite powder. Finally, the authors also suggest that applying a chemical bleaching (or oil separation) stage to the granite powder may be important for the removal of any oil traces left from the processing stages in which the waste was generated.

\section{Energy generation by-products}

The use of coal-fired power stations is still, despite of the developments in alternative energy technologies, a major process for the generation of electricity worldwide. In fact, according to a 2014 investigation [30] coal fired power stations still burned about 407 million tons of coal for the generation of power, thus producing about $130 \times 10^{6} \mathrm{t}$ of coal ash annually. Furthermore, the carbon dioxide emissions inherent to the chemical reaction of burning coal to generate heat, the process also gives rise to a considerable amount of by-products originated by the coal combustion which, in turn, may be utilized in concrete mixtures, as they are mainly composed of silica and alumina and can display pozzolanic behavior.

\subsection{Coal fired power plants}

\subsubsection{Fly ash}

One of the wastes produced by the combustion of coal is fly-ash (CFA). This material is obtained through electrostatic precipitation of the burned fuel particles that are driven out of coal-fired boilers together with the flue gases and may present a viable alternative to, at least, partially replace a material as expensive and highly 
Table 1

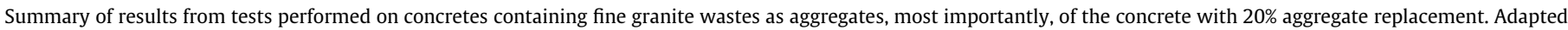
from [28].

\begin{tabular}{|c|c|c|c|c|}
\hline \multirow[t]{2}{*}{ Concrete property } & \multicolumn{4}{|c|}{ Fine aggregate replacement rate (Wt.) } \\
\hline & $0 \%$ & $20 \%$ & $60 \%$ & $100 \%$ \\
\hline Compressive strength, 28 days [MPa] & 52.0 & 55.0 & 47.5 & 31.5 \\
\hline Flexural strength, 28 days [MPa] & 5.84 & 6.17 & 5.68 & 4.91 \\
\hline $\mathrm{UPV}[\mathrm{m} / \mathrm{s}]$ & 5272.9 & 5370.4 & 5008.4 & 4064.7 \\
\hline Water absorption [\%] & 4.00 & 3.81 & 4.15 & 4.77 \\
\hline Percentage of permeable voids [\%] & 9.85 & 9.68 & 10.15 & 10.97 \\
\hline Water penetration depth [mm] & 33.0 & 29.6 & 40.3 & 53.0 \\
\hline $\mathrm{T}_{500}$ time $[\mathrm{s}]$ & 3.97 & 3.15 & 5.19 & 8.01 \\
\hline
\end{tabular}

energy intensive as is cement in concrete mixtures (which may justify the lack of existing research focusing on the replacement of fine aggregate for CFA in concretes).

Coal ash is an aluminosilicate material which, when used in concrete, should contain minimum amounts unburned carbon and sulfates. Also, the ash must comply with [31] as the iron or pyrite content may lead to undesirable concrete leaching. [32,33] studied the mechanical strength and abrasion resistance of concretes in which a partial substitution of fine aggregates for CFA (class F) was performed. The 28-day compressive strength results show that the substitution is beneficial to the concrete. In fact, for a 1 year curing age, the maximum replacement ratio used (40\%) yielded a near 100\% gain in compressive strength in relation to the control concrete. In a similar fashion, the values obtained for the resistance to wear by abrasion suggest a reduction trend in depth of wear as the aggregates were increasingly replaced by CFA. In fact, at 365 days curing age, the $40 \%$ aggregate substitution rate lead to a $42 \%$ reduction in depth of wear. Additionally, splitting tensile and flexural strength and modulus of elasticity results show that the concretes with a 50\% fine aggregate substitution rate display a considerable improvement in all properties at one year curing age (26\% increase for splitting tensile and flexural strength and $18 \%$ for the elastic modulus). This behavior can be explained by the pozzolanic quality of CFA, which causes the improvement of the cement-aggregate matrix. Despite the mentioned existing literature on the subject, there are still areas not covered by the research, namely the durability performance of the fly ash concretes. Nevertheless, this is understandable due to the many valuable potential applications for fly ash in cementitious materials.

\subsubsection{Bottom ash}

Similarly to CFA, coal bottom ash (CBA) is generated during the calcination of coal and is the result of the accumulation, in the furnace, of the non-combustible materials contained in coal. CBA particles are coarser and heavier than fly ash grains and possess a size distribution similar to that of river sand. Furthermore, this waste is, chemically, mainly comprised of alumina (in a higher concentration than in CFA), silica and (to a lower extent) iron oxide, with lower quantities of calcium, potassium and magnesium sulfate and trace percentages of sulfur compounds, $\mathrm{P}_{2} \mathrm{O}_{5}, \mathrm{TiO}_{2}$ and others [34]. On the other hand, [30,35,36] showed that CBA possesses lower specific gravity and much higher water absorption than natural sand. Nevertheless, [37] state that, in order for CBA to display pozzolanic behavior, the chemical properties of the ash must follow the requirements contained in ASTMC618 for fly ash of the C or F class. Moreover, the same authors argue, the waste must be ground until the particles retained on a $n^{\circ} 325$ sieve represent at least $25 \%$ of the total weight.

As to the performance of concrete containing CBA aggregates, $[30,35,36]$ found that the replacement of fine aggregates for CBA promoted a decrease in the workability of these compositions. In fact, [36], which utilized the coarse fraction of CBA, together with mineral admixtures (blast furnace slag and silica fume) and a poly- carboxylic SP, observed that an even lower concrete workability was achieved, while also reporting that the cement matrix of the concrete samples present a significant void content (Fig. 3).

Furthermore, [30] showed that the replacement of fine aggregate for CBA leads to a decrease inbleeding and in the loose bulk density of concrete compositions. Simultaneously, the concrete's long term (180 days) permeable pore space and water absorption by capillarity were both negatively affected by the CBA incorporation. In relation to compressive strength,[30,35,36] found that replacing the fine aggregates for $\mathrm{CBA}$ does not lead to a reduction in this property. Additionally, [30,35] report an improvement in splitting tensile strength (which may be due to the fact that CBA improves the structure of the paste and that this parameter is more susceptible to quality of the cement-aggregate matrix). Moreover, $[30,36]$ further found that the fine aggregate replacement resulted in a reduction in the concrete's elasticity modulus.

\subsubsection{Boiler slag}

Another by-product of energy generation produced in coal-fired power plants is coal boiler slag (CBS). This waste is a coarse, dark, hard, angular, smooth and glassy material, usually found at the bottom of slag-tap and cyclone furnaces and is the result of water quenching the molten bottom ash that accumulates in this furnaces. [38] used coal boiler slag as a partial replacement for coarse aggregates in concrete samples containing microsilica and a polycarboxylic ether superplasticizer. According to EDS scans, the used CBS was composed of $51 \% \mathrm{SiO}_{2}$ (in the form of crystallized quartz), 23.7\% $\mathrm{Al}_{2} \mathrm{O}_{3}$ and $4.9 \% \mathrm{Fe}_{2} \mathrm{O}_{3}$. Further mineralogical analysis (XRD) revealed the overwhelming presence of two mullite phases $\left(74 \%_{3}-\right.$ $\mathrm{Al}_{2} \mathrm{O}_{3 \cdot 2} \mathrm{SiO}_{2}$ and $24 \%{ }_{2} \mathrm{Al}_{2} \mathrm{O}_{3 \cdot 2} \mathrm{SiO}_{2}$ ) and a much lower (4\%) presence of ilmenite $\left(\mathrm{FeTiO}_{3}\right)$.

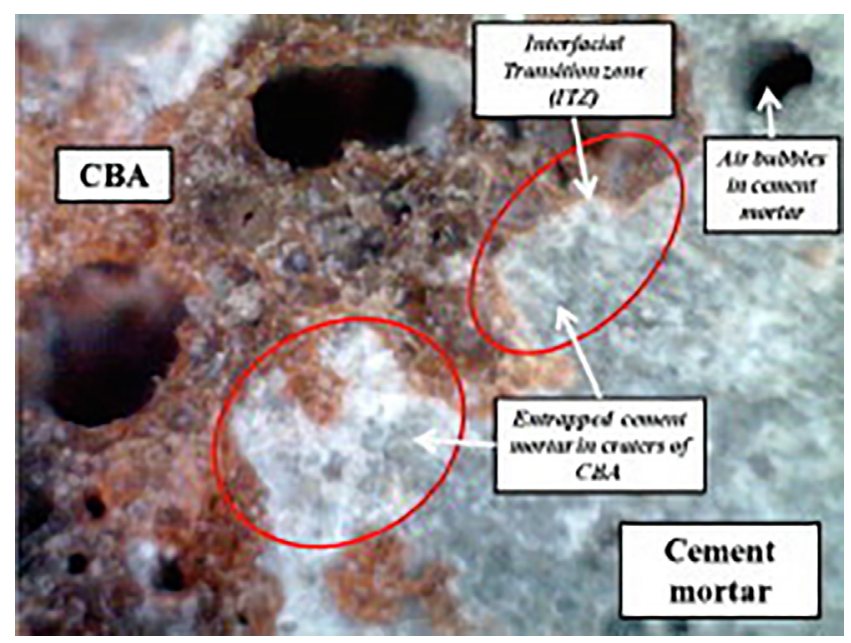

Fig. 3. Image of a $240 \mu \mathrm{m}$ by $180 \mu \mathrm{m}$ section of the surface of a concrete containing CBA in which large air bubbles are clearly visible [36] 
The tests performed by the same authors in concrete samples containing CBS aggregates showed that the addition of slag implies an increase in open porosity and water absorption, and also, a small reduction (up to 8\%) in the bulk density of the concrete. In relation to compressive strength, growing amounts of slag content caused proportional upgrades in strength (for a maximum of $23 \%$ increase at 28 days and a $19 \%$ rise at 56 days for the sample with the highest slag content). Moreover, although the concretes demonstrated a splitting tensile and flexural tensile strength increase, the optimal slag content was found to be $10 \%$ (which caused a $9 \%$ and $18 \%$ increase in splitting tensile and flexural strength, respectively). The authors justify this behavior by the fact that, for this replacement rate, the available cement causes the upgrade of the pore structure, as it completely fills the largesized slag pores. The study also observed that the cracks caused by the mechanical actions to the concrete samples, propagated both via the rough boiler sand particles, as well as the smooth gravel aggregate. In relation to the modulus of elasticity property, all the samples containing slag revealed a negative correlation between the amount of slag and this modulus. More specifically, the 56 days elasticity modulus of the sample containing the maximum slag content suffered the maximum registered reduction in the elasticity modulus (33\%) relative to the control sample, which the investigation attributes to the elevated internal porosity of the slag.

\section{Metallurgy industry wastes}

The global metallurgy industry is a major source for industrial waste and the integration of a large number of wastes generated from producing and processing ferrous and non-ferrous metallurgic products in the composition of construction products has recently been the focus of intense research efforts. Of these, this investigation highlights the studies on the application of iron and steel-making slags, spent foundry slag, granulated steel and copper and imperial smelting furnace slag as aggregate in concrete. As to the availability of the more prominent ferrous slags, [39], citing data sourced from EUROSLAG (which is, however, more than ten years old) highlighted the fact that in the EU, roughly 48 million tonnes of these wastes are generated annually. According to the same dataset, ground granulated blast furnace slag accounted for the biggest share of waste generation (about 43\%), followed by basic oxygen furnace slag (around $23 \%$ of the total)

\subsection{Iron production}

Slags that originate from the production of pig iron in blast furnaces can be either water or air cooled. The first method produces ground granulated blast furnace slag (GGBFS), which cools rapidly and is vitreous in nature. The air cooling, however, creates a rocklike slag, with low cementing qualities, which is termed air cooled blast furnace slag (ACBFS). In a similar fashion, when cupola furnaces are used to produce cast iron (secondary process), the generated slag is very similar to blast furnace slag and can also be air or water-cooled, thus forming two different types of slag: air cooled or granulated cupola furnace slag (CFS). Nevertheless, despite their similarity to furnace slags, cupola slags have been found ,as further detailed in this section, to possess less appealing properties for potential use as aggregates in concrete.

\subsubsection{Ground granulated blast furnace slag}

Due to is highly pozzolanic nature, GGBFS is already thoroughly used in concretes, either as a replacement, or as a supplement to cement. $[40,41]$ studied the influence of the partial substitution of fine aggregates for GGBFS on the properties of concretes having found that, when compared to natural aggregate, GGFS possesses lower specific gravity and higher water absorption. As to its resistance to wear, [41] found that it is three times higher than the one displayed by natural sand, while [40] observed the rough surface, angular shape and the glassy nature of the GGBFS particles (which the authors state are mainly composed of rankinite and dicalcium silicate). Moreover,[42] also observed, through EDX analysis, the rough surface of GGBFS particles, adding that this same surface is of a glassy nature.

Furthermore, tests to concretes containing these wastes as aggregates showed that the workability of the mixtures was greatly decreased by the GGBFS addition [40]. This phenomenon, however, was not observed by [41], although the authors formulated compositions in which, as the GGBFS content was increased, a decreasing amount of limestone filler was added to the mixture, which (in our view) skews the workability results. Moreover, $[40,41]$ agree, that up to a $60 \%$ fine aggregate for GGBFS replacement, compressive strength steadily increases (in tandem with the waste addition), which is attributed to the pozzolanic behavior of the slag as it reacts with calcium hydroxide and forms a secondary calcium silicate gel. The same exact positive trend was also observed by [40] when studying the influence of the slag in the splitting tensile strength of the concretes. Also, this investigation also focused on the soundness of concrete quality (rebound hammer test) and the results show a significant improvement in this property, which is attributed to the reduction in the voids of concrete produced with GGBFS. Meanwhile, [41] performed mercury intrusion porosimetry analysis (MIP) and found that, when the slag content of the samples is increased and the volume of the cement paste is maintained, although the pores' diameter decreases, the pore volume actually increases. Furthermore, the investigation also found that the autogenous shrinkage of the concretes containing slag increases proportionately (with a $60 \%$ slag incorporation leading to a $33 \%$ higher autogenous shrinkage). Also, slag addition was also reported to lead to higher drying shrinkage, causing a total shrinkage increase of $10 \%$ for a $60 \%$ aggregate replacement. This result is attributed to the higher porosity and fines content of the slag.

\subsubsection{Air cooled blast furnace slag}

As to ACBFS, [43] observed that the narrowness of the particle size distribution of the slag and that the irregularities and cavities of the coarse particles' surface can potentially affect the compactation of concretes. This observation is also confirmed by a previously mentioned study [42]. Moreover, ACBFS was also found to possess lower density and higher water absorption,while leading to a reduction in workability of concrete mixes, even when a polycarboxylic ether superplasticizer is used. Furthermore, density, compressive and splitting tensile strength of concrete mixes were also highly negatively affected by the slag additions (Table 2). Moreover, the study states that the presence of heavy metals (Se, $\mathrm{Ba}, \mathrm{Cr}, \mathrm{Cu}$ ) in concrete leaching does not fulfill the limits established in all the available legislation consulted, therefore limiting the potential use of ACBFS in concrete.

Table 2

Results of the tests performed on ACBFS concrete, where the deleterious influence of the fine aggregate replacement can be observed. Adapted from [43].

\begin{tabular}{lll}
\hline Concrete property & \multicolumn{2}{l}{$\begin{array}{l}\text { Fine aggregate replacement } \\
\text { rate }(\mathrm{Wt})\end{array}$} \\
\cline { 2 - 3 } & $0 \%$ & $50 \%$ \\
\hline Density $\left[\mathrm{kg} / \mathrm{m}^{3}\right]$ & 2.28 & 2.21 \\
Compressive strength [[MPa] & 41.2 & 26.5 \\
Tensile strength [MPa] & 3.3 & 2.9 \\
Young's modulus [GPa] & 29.2 & 25.7 \\
\hline
\end{tabular}


Meanwhile, [44] also found that the replacement of coarse natural for ACBFS aggregates induces the reduction of workability, density, mechanical strength (compressive and splitting tensile) and elastic modulus in concrete compositions being that the reduction is amplified when smaller sized aggregates $(10 \mathrm{~mm})$.

\subsubsection{Cupola furnace slag}

Cupola furnace slag (CFS), even when very finely ground, possesses much lower pozzolanic reactivity than fly ash, or even, blast furnace slag [45]. Furthermore, [42] also found that these slags possess higher acidity, lower pozzolanicity and a highly crystalline structure.

Nevertheless, [46] studied the potential application of CFS as partial fine aggregate substitution in concretes. The investigation found that a cupola slag substitution of $25.5 \%$ in weight originated a marginally lower workability while not altering the volume density and air content of fresh concrete mixtures. Additionally, for all curing ages, the compressive strength reduction observed in the slag concrete, when compared to standard mixes was found to be slight to negligible. Similarly, the dynamic and Young's modulus of elasticity, water absorption by capillarity and resistance to water flow penetration properties of the slag concretes are stated to be similar to the reference mixes. Nevertheless, the resistance of the CFS concretes to freeze/thaw cycles, measured through the analysis of flexural strength under these cycles, did not meet the local (Slovenia) regulatory standards. This phenomenon was attributed by the authors to the low entrapped air of the mixtures. Finally, the microstructure analysis (XRD) of the reference and CFS concretes revealed minimal differences between the concretes as they both were characterized by large total pore volumes, relatively high pore-specific surface area and large amounts of total porosities. This observation leads the authors to conclude that the addition of CFS in concrete leads to a refinement of the pore structure.

\subsection{Steel-making}

\subsubsection{Basic oxygen, electric arc, and ladle metallurgy slags}

The two types of furnaces nowadays used in the production of steel from metal scraps generate, in turn, two slag varieties: basic oxygen furnace (BOF) and electric arc furnace (EAF) slag. These steel industry by-products are non-metallic ceramic materials produced from a reaction between a purifying flux (calcium oxide, dolomite or limestone, among others) and the non-metallic components of the steel scrap. The chemical composition of these wastes is primarily $\mathrm{CaO}, \mathrm{FeO}$ and, in lower percentages, $\mathrm{SiO}_{2}$. Additionally, according to [47], the main mineral phases of steel slags are dicalcium silicate $\left({ }_{2} \mathrm{Cao}-\mathrm{SiO}_{2}\right)$, dicalcium ferrite $\left({ }_{2} \mathrm{CaO}-\mathrm{Fe}_{2} \mathrm{O}_{3}\right)$ and wüstite ( $\mathrm{FeO})$. Moreover, special attention needs to be paid to the $\mathrm{MgO}$ and free lime content of the slags, as these elements can lead to volumetric variations in concretes. Also, the same authors also found that steel slags possess high bulk density, impact and crushing strength, polished stone value and binder adhesion. Furthermore, these slags tare shown to possess much finer fractions than their dolomite equivalents, and also, to have a water absorption similar to the one possessed by natural aggregates. Also, due to the high iron content, these wastes, also when compared to their natural equivalents, were found to display higher specific gravity and unit weight.

As to the substitution of fine aggregates for BOF in concretes, [48] utilized this waste (while also using nano-silica) to produce cement concretes and reported that, despite the use of a polycarboxylic superplasticizer, the mixtures' workability decreased for higher contents of BOF. Also, the results show an increase in the fresh, dry and saturated surface dry density of the concretes which, the authors argue, is caused by the higher density of BOF, in relation to natural sand. Furthermore, the authors observed a slight upgrade in the concrete's compressive, splitting tensile and flexural strength, and also, modulus of elasticity and ultrasonic pulse velocity. Additionally, in what the authors suggest is a consequence of the pore refinement of the concrete matrix (in turn caused by the slag's finer nature), the increase in the rate of sand substitution led to the reduction in water absorption. Moreover, the addition of nano-silica proved to induce the reduction of the width of cracks in concrete samples while the gradual substitution of fine aggregates for BOF did exactly the opposite. In reality, it promoted the development of increasingly larger cracks, as the total substitution of fine aggregates yielded a $160 \%$ increase in the width of cracks which, the study states, may be due to the increased shrinkage observed in samples containing BOF. Meanwhile, another study [49] also showed that, despite also using a carboxylate superplasticizer, high rates of replacement of fine aggregates for fine BOF and EAF drastically decreased workability. Nevertheless, up to the maximum established limit of slag content (25\%), the gradual increase in slag correlated positively with the rise in the 28-day compressive, flexural and splitting tensile strength, density and Young modulus. However it is also shown that the drying shrinkage of the concretes is considerably worsened by the presence of EAF as a $25 \%$ substitution rate leads to a $30 \%$ shrinkage increase.

As regards to the coarse fraction of the BOF and EAF slags, [50] focused on the important expansion issues that may arise in concretes containing these wastes as aggregate. In fact, the shrinkage phenomenon that can be observed in concretes containing these slags may be linked to the impurity removal process used in the steel-making process. More specifically, the addition of free calcium oxide and/or free magnesium oxide in the manufacture of steel introduces elements that expand when hydrated and can have detrimental effects in the quality of the concrete. In the mentioned investigation, autoclave expansion tests performed on the slags showed that BOF slag (which contained the highest estimated free $\mathrm{CaO}$ content) experienced the highest expansions, while EAF expansions were observed to be close to negligible and natural aggregate underwent no expansions (Table 3). On the other hand, EAF slag aggregates displayed a rougher surface and a more angular shape than BOF slag particles, while both slags also demonstrated, when comparing to natural aggregates, higher specific gravity and unit weight.

In relation to the tests performed on concretes containing these slags as aggregates, BOF concrete, with a 28-day compressive strength $10 \%$ lower than the one displayed by the reference sample was the worst performing concrete. EAF replacement, in turn, did not lead to reductions in compressive strength. Splitting tensile strength test results indicate, however, that the presence of both steel slags induces considerable losses in strength (although less exacerbated in the case of EAF). The different behavior observed in the strength development of the waste concretes can be due, as the authors argue, to the better mechanical interlock between the cement paste and the aggregates for the case of EAF concrete (whose particles possess a rougher surface and a more angular shape). Moreover, the measured free drying shrinkage of these concretes was higher than the reference concrete, thus proving the detrimental effects of the presence of $\mathrm{CaO}$ and $\mathrm{MgO}$ in the slag

Table 3

Results from autoclave expansion tests performed to particles of steel-making slags and dolomite versus their estimated free $\mathrm{CaO}$ content. Adapted from [50].

\begin{tabular}{lll}
\hline Slag & Estimated free CaO [\%] & Expansion rate [\%] \\
\hline BOF & 3.4 & 8.8 \\
EAF & 0.1 & 0.1 \\
EAF/LMF & 0.4 & 0.8 \\
Dolomite & - & 0.0 \\
\hline
\end{tabular}


composition. In fact, [51] argue that, when hydrated to the hydroxide form, these elements cause topochemical reactions and stress concentrations, which may lead to micro-cracking in confined or bound applications in concrete. Furthermore, steel slag additions upgraded the fracture properties of the concretes and led to a slightly lower freeze/thaw resistance (although the authors regard this resistance as still being situated within acceptable values). In turn, [52] studied compositions with full replacement of coarse aggregates for EAF slag and obtained slightly different results. In fact, contrary to the previously mentioned study (in which the aggregates were used in saturated surface dry condition), the researchers mixed the aggregates in the dry state while adding a superplasticizer to the composition (therefore altering significantly the binding properties of the mixtures). More specifically, the workability of the mixtures was greatly reduced and unit weight increased. Moreover, compressive (short and long term), splitting tensile and flexural strength all improved. Also, depth of wear and porosity properties all increased for EAF concrete while the resistance to water flow and to freeze-thaw de-icing salts were not impacted.

Meanwhile, a recent study on the topic of concrete containing both fine and coarse BOF aggregates [53]. In this study, the authors made use of a polycarboxylate superplasticizer and thus was able to assure proper workability in the vast majority of the compositions studied. Moreover, the study found that a simultaneous $50 \%$ fine and 30\% coarse natural aggregate replacement (in weight) leads to a concrete with a 19\% 90-day compressive strength improvement. Additionally, it was acessed, through MIP testing, that the pore volume and diameter were significantly reduced, while the bulk density and was increased, when compared to the reference concretes. Finally, the SEM analysis performed also revealed an ITZ upgrade.

Ladle metallurgy furnace slag (EAF/LMF) is generated when electric arc furnaces (and secondary industrial processes are implemented) are used for producing steel. This by-product is similar to standard EAF although, as additional alloying fluxing agents are used in production process, the slag may possess a different chemical composition. In relation to the previously mentioned autoclave expansions testing, [50] studied coarse ladle slag and reported that its performance is better than the one displayed by BOF and somewhat worse than EAF's. In turn, [54] addressed the partial substitution of fine aggregates for ground EAF/LMF in self-compacting concretes (SCC) containing a set retarding agent and a polycarboxylate ether superplasticizer. The authors reported that the workability of the slag concretes was substantially inferior to the reference samples. Furthermore, compressive strength, water absorption by capillary action and carbonation, chloride and freeze/thaw resistance were all upgraded by the presence of EAF/ LMF. It is to be noted that, once more, the workability differences observed skew the analysis of the influence of the slag in concrete compositions.

In a more recent investigation concerning the same research topic [55], and although the focus was limited to the use of high silica EAF/LMF as replacement of aggregates in self-compacting structural mortars, the authors found that carefully designed compositions also containing a plasticizer, EAF slag and fly ash (in a total of $60 \%$ substitution, in volume, of natural materials for slags) yielded self compacting mortars possessing satisfactory characteristics. In fact, the workability, long term compressive strength, porosimetry and microstructure of the mixtures was similar to the reference mortars. Nevertheless, detrimental effects of the wastes can be felt in the short term compressive strength results of the compositions. Also, a slight to negligible drying shrinkage and expansions increase was detected in mortars containing the slags, although the authors state that the magnitude of this increase was situated within the limits set in local regulations.
Finally, the researchers recommend an LMF/EAF content in a proportion of $20 \%$ of the total binder amount

\subsection{Molding and casting}

\subsubsection{Spent foundry slag}

It is standard practice, in the steel industry, to use high quality silica sand in the casting process. This material is then re-used several times until it no longer displays the same performance, by which time the sand becomes waste. This residue is a clay bonded sand termed spent foundry sand (SFS) and is usually mainly composed of silica (with small percentages of bentonite clay, carbonaceous additives and water). When compared to natural sand, SFS typically possesses similar specific gravity and water absorption, and also, higher fines content [56,57]. Additionally, [56] observed that the SFS used on the investigation (of the fraction $<2 \mu \mathrm{m}$ ) possessed a $5 \%$ active clay content. The same authors studied the replacement of sand (and cement) for SFS in concretes, in which water reducing agents were not used, and limited the fraction of SFS passing the $\mathrm{N}^{\circ} 200$ sieve, as ASTMC33 stipulates, to a $4 \%$ of the total mass of sand. The study found that the inclusion of SFS, as is corroborated by [57], caused a reduction in workability. Furthermore, SFS substitution leads to a compressive and splitting tensile decrease [57,56], while the elasticity modulus is also impacted [56]. On the other hand, the same investigation states that the water absorption and voids content were improved by the presence of SFS in a rate of at least $5 \%$ of the fine aggregates' weight, which the authors argue is the result of the void-padding effect of the clay-type materials present in the foundry sand. Meanwhile, [57] also confirms the matrix improvements when using up to a $30 \%$ SFS replacement and to a 365 days curing age (Fig. 4). Nevertheless, it is also reported that the resistance to freeze-thaw cycles is lowered by the addition of SFS.

\subsubsection{Recycled granulated steel}

Meanwhile, [58] confirms that, even when polycarboxylate ether superplasticizers are use, the workability of concretes containing SFS as fine aggregate decreases. Furthermore, compressive strength, dynamic elastic modulus, surface sorptivity and water permeability were all impacted by the waste addition.

Recycled granulated steel (RGS) is a by-product of the manufacture of reinforcement bars in steel rolling mills. This waste is usually remolded in a steel plant, and thus, already possesses commercial value. Nevertheless, the re-molding process implies

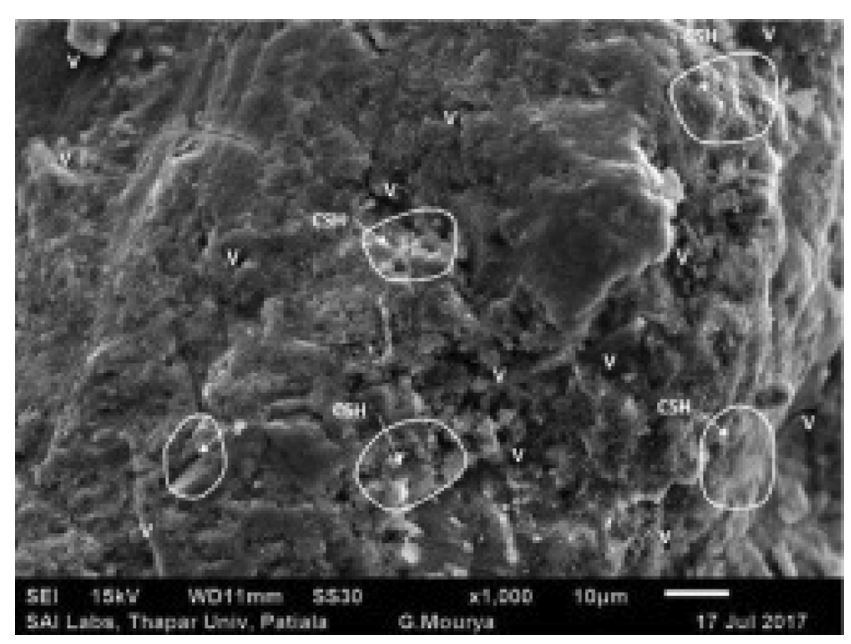

Fig. 4. SEM micrograph of a SFS concrete containing a 30\% aggregate replacement at 365 day curing age in which the location of voids, and CSH gel is indicated [57]. 
the generation of carbon emissions and the potential use of this product in concrete production could, in theory, present a more sustainable recycling path for this material. [59] studied the implications of the utilization of RGS as partial substitution of fine aggregates in concrete compositions and found that RGS, when compared to natural aggregate, possesses higher specific gravity and lower water absorption. Also, contrary to the majority of recycled aggregates, the addition of RGS was reported to increase the workability of mixtures. Furthermore, the compressive and splitting tensile strength test results show that, up to a 50\% fine aggregate replacement, these strengths gradually increase, at which point an inversion of the trend can be observed, and the compressive strength for a $60 \%$ is lower than the reference concrete's strength. The researchers state that this behavior is due to the rough texture of RGS particles, which causes a stronger bond between the binder and the aggregate while also generating greater volume of voids and weaker bonding for higher waste additions. In relation to flexural strength, all the waste-containing concretes returned improved values of strength, being that the mixture that maximized this property was the sample containing $30 \%$ fine aggregate replacement (different than the optimal $50 \%$ substitution for compressive strength). Still according to this study, the strength increase is related to the microfiber-like reinforcement behavior of RGS. Furthermore, the study of geometrical variations originated by the exposure to a sulphate-rich environment did not yield a clear pattern of results as to what the RGS addition concerns. Moreover, after the said sulphates' exposure, only the control concrete increased its residual compressive strength, while the $10 \%$ RGS composition compressive strength was unaltered, and the others saw a mild to moderate reduction in strength due to the same attack. Lastly, the SEM imaging analysis proves that, although the RGS's higher specific gravity favors the creation of a denser matrix, the production of gypsum and ettringitte caused by the reaction of sulphate ions with the cement, and also the lack of available matrix pores, leads to expansions and cracking.

\subsection{Non-ferrous metallurgy}

\subsubsection{Copper slag}

Copper slag (CS) is an industrial by-product of the copper production process. According to [60] (which cites data from a 2015 study by the International Copper Study Group), the global generation of CS by the copper industry was, at the time of the study, of around 68 million tonnes (being that China producers accounted for roughly one-third of the total).This waste is mainly constituted of iron and silicon oxides, and can exhibit pozzolanic behavior. It also typically possesses a $\mathrm{Fe}_{2} \mathrm{O}_{3}+\mathrm{SiO}_{2}+\mathrm{Al}_{2} \mathrm{O}_{3}$ content of over $70 \%$ $[60,61]$ which, according to ASTMC618, is the minimum required by for a class $\mathrm{F}$ fly ash classification. The mentioned studies also agree that CS possesses high specific gravity and low water absorption, when compared to the fine natural sand used in the respective studies. Furthermore, $[60,61]$ found that the use of CS as substitute for fine aggregates leads to an increase in the workability of the mixtures. As to compressive strength, again, the investigations agree that a $20 \%$ addition of slag maximizes the increase in strength relative to the reference sample. Additionally, [61] argues that the strength increase observed for lower aggregate substitutions is attributed to the physical qualities of copper slag, as this material has a better compressibility than sand and can partially relieve stress concentrations. Also, the study states that the angular, sharp edges of copper slag, may improve the cohesion of the concrete matrix and enhance the abrasion properties of the concrete. Moreover, splitting tensile strength is also shown to benefit from the addition of CS, while the opposite phenomenon occurs in terms of flexural strength, as it induced a detrimental effect to the results of this property for every sample. Nevertheless, for both strengths, the best performing composition was the one containing $50 \%$ fine aggregate replacement. As to durability-related properties, [61] state that a 40\% CS fine aggregate replacement rate leads to improvements in the initial surface absorption, which the authors attribute to the elevated free water content of the mixture containing the highest proportion of CS (which leads to additional voids in the paste). Moreover, the volume of permeable voids displayed a reduction (relative to the control composition) in samples with up to a 50\% slag content. Meanwhile, [60] confirms the improvements in the initial surface absorption property, although the optimal substitution rate is stated to be lower (20\% of fine aggregate). Finally, the mentioned investigation also tested water absorption by capillarity, sulfate and carbonation resistance, electrical resistivity and ultrasonic pulse velocity, having also observed that a 20\% CS replacement improves the results of the concretes in these properties (despite the slight weight gain of these mixtures when subject to sulfate exposure).

More recently, [62] confirm the improvement (as long as superplasticizers are used) in the fresh properties of self compacting concretes containing fine CS relative to compositions only containing aggregates of natural origin. Furthermore, the investigation also reports the increase in compressive and splitting strength for mixtures containing up to $30 \%$ and $60 \%$ CS, respectively. Moreover, SEM analysis also confirmed that microstructure of the concretes containing was also denser than the ones displayed by reference concretes.

\subsubsection{Imperial furnace slag}

Imperial smelting furnace slag (IFS) is a black, granular and (largely) amorphous material generated as a by-product of zinc refining and can potentially be used for replacing natural aggregates in concrete formulations. In the Rajasthan state of India alone, country which, according to [63] is the world's seventh largest zinc producer, $80 \times 10^{3} \mathrm{t}$ of IFS were, at the time of the mentioned investigation, annually produced (with $650 \times 10^{3} \mathrm{t}$ of slag already stockpiled). As stated in [63-65], the slag is mainly constituted by iron oxide, silica, calcium oxide, alumina, zinc and lower amounts of a wide variety of other chemical elements. Moreover, [63] reports that fine IFS waste possesses higher specific gravity and lower water absorption than natural aggregates. The same investigation also detected, through SEM microscopy, that the waste particles are rough and irregular, again when compared to natural sand. As expected, replacing natural aggregate for fine IFS lead to lower workability in concrete mixtures. Also, the authors argue, as zinc and lead ions leaching tend to induce a retardation of concrete setting, pastes containing IFS aggregates may be affected by this phenomenon. Meanwhile, [64] studied the leaching potential of concrete containing IFS as fine aggregate substitution and found that, although these specimens displayed acceptable lead cadmium and zinc leaching, the setting of concrete will be delayed by the inclusion of this waste. Moreover, the authors also state that the addition of pulverized fly ash or GGBFS is beneficial for the control of leaching in concretes containing IFS. In another investigation, [65] studied the impacts of IFS addition in the retardation of concrete setting, namely through the analysis of the mineralogical phases and heat variations during the cement hydration in concrete compositions. The authors confirm that IFS delays cement setting, which is likely caused by the formation of calcium hydroxyl-zincate or plumbate (instead of originating in a gelatinous surface layer). In fact, this reaction (the authors conclude) consumes calcium and hydroxide ions from the solution and delays the supersaturation and precipitation of calcium hydroxide and the development of $\mathrm{CSH}$ gel. The researchers also found that group II cations additions were the most successful in mitigating setting retardation. It is further important to note that, 
according to the investigation, calcium hydroxide precipitation, in concrete containing IFS, did not occur. Meanwhile, [63] also states that the compressive, flexural and pull-off strength, abrasion resistance, sorptivity and resistance to chloride-ion diffusion, and shrinkage of concretes containing IFS fine aggregates were comparable to the ones displayed by the control specimens. The mentioned research also states that the behavior of the slag concretes may be negatively influenced by the slag's lack of fines (when compared to natural sand). Furthermore, accelerated carbonation test results revealed an upgrade in performance for contents of up to $50 \%$ of aggregate replacement. As the authors note, because carbonation is the result of the chemical reaction between carbon dioxide and cement hydrates, there should not be any change in behavior for IFS concretes, however, the irregular shape of the slag can lead to decreased porosity and to the diffusion of $\mathrm{CO}_{2}$. Moreover the reinforced concrete's corrosion susceptibility was assessed through monitoring the macro and half-cell potential evolution under wetting/drying cycles. The results indicate that a 0.4 $\mathrm{w} / \mathrm{c}$ ratio and a $10 \%$ sand replacement rate, the corrosion resistance is clearly superior to the one of the corresponding control concrete. The authors also revealed that, after performing the cell monitoring tests, the concrete was broken and chemically cleaned and the anodic bars were then analyzed for the presence of brown rust, which was indeed detected. Also, in a few, sparse, locations a black corrosion product was observed (which can be originated by the lack of oxygen).

\section{Thermoplastics}

Wastes originating from thermoplastic materials are abundant and present a serious environmental hazard. According to [66], the annual generation of plastic wastes, only in Western Europe, was, at the time of the study, of $23 \times 10^{6} \mathrm{t}$. This synthetic material is thoroughly used in a great number of human activities and, after being used, a safe deposition method is difficult to find, which causes serious environmental consequences, most notably, to marine ecosystems. Consequently, worldwide adoption of the reutilization of thermoplastics in the construction industry would constitute a major environmental breakthrough and, as such, considerable research has been performed to integrate these wastes in concrete production.

\subsection{Plastic wastes from various sources}

\subsubsection{Polyolefins}

Polyolfins are a secondary raw material that can be obtained by the plasticization and densification (by extrusion) of the polymeric fraction of industrial wastes. The material obtained through this process is in turn, composed of polyethylene, polypropylene and polyethylene terephtalate, all of which are widely used in the plastics industry. [66,67] studied OPC concretes and mortars in which the natural aggregates were partially replaced by polyolefin waste. [67] observed a linear decreasing trend in the apparent density of concretes as the waste content increased. Furthermore, these density results were all inferior to $2000 \mathrm{~kg} / \mathrm{m}^{3}$ and, following the guidelines of the European standard [68], all the concretes produced may be classified as lightweight. This phenomenon, the authors argue, is the result of the plastic's lower specific weight. Simultaneously, the research observed that the waste addition caused an increase in the open porosity and water absorption of concrete samples. Moreover, SEM microscopy analysis (Fig. 5) and mercury intrusion porosimetry evaluation also demonstrated that polyolefin concrete possesses a matrix with higher heterogeneity and larger pores $(>1 \mu \mathrm{m})$ when compared to a standard concrete which, the researchers justify, is the result of increased

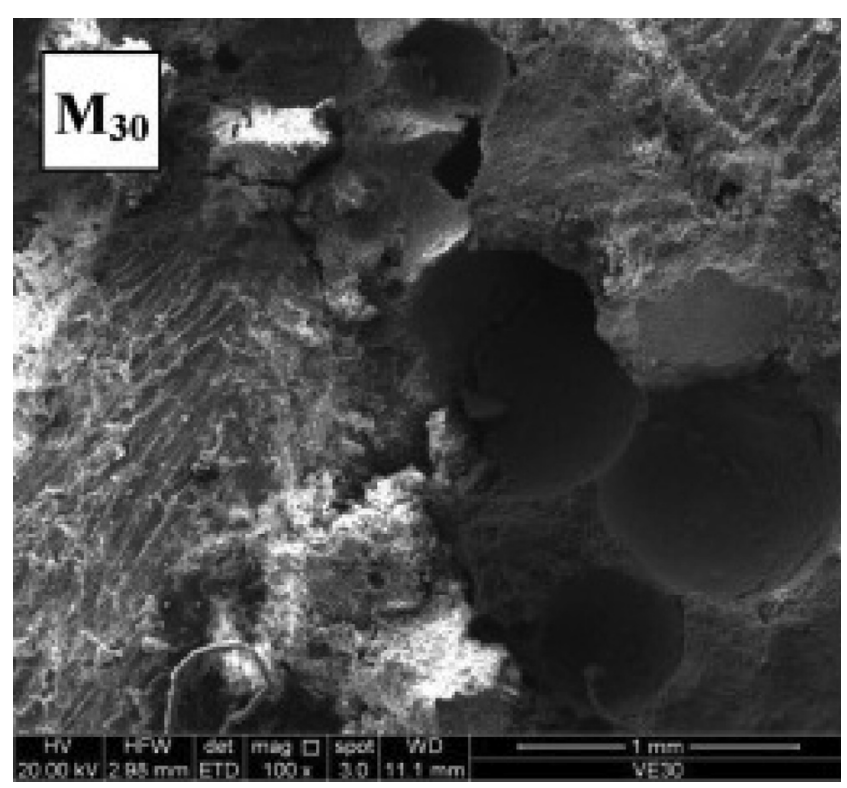

Fig. 5. SEM image of a concrete containing 30\% replacement of aggregates for polyolefins. The image shows the weak concrete matrix of the sample [67].

entrapped air present in the mixtures containing plastic waste. As to the workability of the samples, the addition of waste, despite the use of an acrylic superplasticizer, negatively influenced this property. Furthermore, compressive strength tests showed it was also impacted by the addition of plastic, while a strong correlation $\left(R^{2}=0.97\right)$ was observed between the waste addition and the strength reduction. The authors justify this occurrence with the lower strength of the waste, when compared to that of natural aggregates, with the weak plastic-cement bond and, lastly, with the hydrophobic nature of plastic (thus slowing down or preventing the hydration of the cement powder). Nevertheless, splitting tensile strength results indicated an optimal aggregate replacement rate of $10 \%$ in volume. The authors argue that this result is a consequence of the fiber-like behavior of the plastic particles, which, up to the mentioned rate, is more beneficial than the detrimental effect of the waste's addition on the strength. Moreover, ultrasonic pulse velocity tests also revealed a very strong correlation between the waste content increase and the downgrade in the performance of the concrete $\left(R^{2}=0.99\right)$. As to the thermal stability of concrete samples, the study shows that a temperature of $600^{\circ} \mathrm{C}$ causes a deterioration in the apparent densities, dynamic elasticity modulus and strength that is proportional to the waste content of the samples (while the compressive strength of the reference OPC concrete, at the same temperature, is not impacted). The researchers conclude stating that, while this waste material adds environmental value to the mixtures, it can only be considered for non-structural lightweight concrete applications. On the other hand, mortar tests conducted by [66] in which the replacement of the fine natural aggregates for polyolefin wastes demonstrated that this material leads to lower thermal conductivity and water vapor resistance, which indicates that these wastes can be utilized when mortars with thermal insulation and dehumidifying properties are required.

\subsubsection{Polyethylene terephtalate}

One of the components of polyolefins is a material used for the production of most plastic containers is polyethylene terephtalate (PET). This waste is responsible for major worldwide environmental impacts and most notably, to marine ecosystems. [69] used crushed PET bottles as partial substitution of coarse and fine aggre- 
gates in OPC concrete compositions using three types of wastes: fine $(\mathrm{PF})$ and coarse $(\mathrm{PC})$ shredded and sieved PET, and lastly, fine heat treated spherical/cylindrical pellet-shaped PET (PP). As to the physical properties of the waste, the data revealed that, when compared to natural aggregate, it possesses lower density and water absorption.

As to the fresh properties of the concrete containing PET aggregates, the visual analysis of the mixtures suggests that, for PP waste, and due to the spherical shape and smooth surface of its grains, higher additions of this material lead to a slightly increased workability. In opposition, PF and PC additions cause a reduction in workability, which is attributed to the sharper, more angular and non uniform shapes of PET aggregates. Furthermore, the authors also observed that concrete containing 15\% PF (and several of the PC compositions) displayed sample segregation which, they argue, may be caused by the higher $\mathrm{W} / \mathrm{C}$ ratio. Also, due to the PET aggregate's lower density, all the samples containing recycled aggregates suffered a decrease in density, relative to the control specimens, which was proportional to the amount of recycled aggregates added. Compressive strength results, both at 7 and 28 days, confirm the reduction in compressive strength as PET content is increased, especially for the case of PC aggregates. Meanwhile, although PP concrete performs better in compressive strength tests (which can be attributed to the lower w/c ratio of these compositions), when comparing to other PET aggregates, it still underperforms natural aggregate, in what seems to be a consequence of the grain's smoothness (decreasing the binding between the aggregate and the cement paste). Additionally, unlike PC and PF, the particle size distribution is artificially uniform and downgrades effectiveness of the grading curve. The same trend can be observed to the results of the concretes in a property which is largely dependent of the ITZ characteristics: splitting tensile strength. According to these tests, PP continues to be the best performing addition, followed by PF and ending with PC. Nevertheless, the authors remark that, after failure, the PP grains debonded from the matrix, which further hints at a weak bonding between PP and the cement paste. In relation to the modulus of elasticity, the investigation found that the deleterious effect of the PET aggregates could be observed for all types of additions used, which is attributed to the lower elastic deformation of the PET aggregate, and also, to its higher porosity. Furthermore, PP also performed better than PF and PC (in this order) in flexural strength tests (with the added curiosity that the shape of PF and PC grains caused the test specimens not to split in two after the failure occurred). In reality, the authors argue, PET particles bridged the crack and prevented brittle failure (contrary to PP and natural aggregates). Also, abrasion test results show that this property may benefit from the inclusion of PET aggregate. In fact, while PP additions lead to the improvement the abrasion results (depth of wear), PC and PF additions, however, also originated the upgrade of the specimens, but only up to a $10 \%$ aggregate substitution. Additionally, PF aggregates performed worse than PC additions in weight loss due to abrasion which, it is stated, is the result of the particles easily departing from the cement matrix.

In a related study, [70] studied the durability behavior of concretes in which fine or coarse natural aggregate was replaced by shredded PET waste bottles. The authors observed that the workability decreased for the addition of either coarse or fine plastic aggregates. The waste additions also lead to lower density and higher water absorption by immersion and capillarity, carbonation depths and chloride migration coefficients. However, lower drying shrinkage values (relative to the reference concrete) were also observed. The study concludes stating that the addition of finer, smoother and more regularly shaped plastic particles (as in the case of plastic pellets), favors the durability performance of the PET concretes. In a more recent investigation, [71] also utilized used shredded PET bottles for the substitution aggregates in concrete compositions, only this time, the authors only focused on the partial replacement of the fine fraction of the aggregates (PF). As to the results of the study, the researchers confirm that, despite the use of a superplasticizer, the workability is impacted by the introduction of PF. Moreover, the water absorption rate of the concretes containing only a $20 \%$ PF aggregate content increased by $55.4 \%$, when compared to the reference sample. Nevertheless, a $12.5 \%$ aggregate replacement rate led to considerable improvements in compressive, splitting tensile and flexural strength (by 43, 27 and 30\% respectively). Furthermore, density, pulse velocity and elastic modulus are also negatively impacted by the aggregate replacement, although an aggregate replacement rate of only $12.5 \%$ induces an improvement of $108 \%$ in energy absorption and, as expected, the observation of the concrete samples' failure mode indicate that the gradual increase in the addition of PF leads to a corresponding upgrade in the concretes' ductility

\subsubsection{Polyvinyl chloride}

Another thermoplastic waste that has attracted significant research attention for potential use as aggregate replacement in concrete compositions is Polyvinyl chloride (PVC), a material which can be found in a wide array of construction applications. [72] investigated concrete compositions containing a partial replacement ( $5 \%$ to $85 \%$ in volume) of natural aggregates for material of the $0-10 \mathrm{~mm}$ fraction, obtained from a two stage crushing of PVC sheets. PVC particles were found to be finer than gravel and coarser than river sand. Furthermore, the authors observed that they possess high surface area, are flaky and heterogeneous in shape. Moreover, when compared to natural aggregates, the PVC waste displays significantly lower specific gravity and bulk density. Consequently, PVC concretes, especially for replacement rates of over $30 \%$ of fine and $45 \%$ of coarse aggregates, and even though the fine natural aggregates were used in a saturated surface dried state, demonstrated lower workability, which the authors attribute to the shape and size distribution of the PVC grains. Also, as the PVC content of the concretes is increased (particularly in the case of coarse aggregate substitution) density decreases accordingly. As to water absorption results, the tests show that this property, particularly for coarse aggregate replacements of over $30 \%$, is affected by the PVC addition. Plus, this trend can be observed for both the replacement of coarse and fine aggregates and is visible in initial and final absorption values. This result is attributed to the flakiness of the PVC particles, which induce the formation of a pore transition zone and increase macro cracks in the concrete. In relation to mechanical strength, the study shows that a fine or coarse substitution of up to $15 \%$ does not lead to meaningful changes in compressive and splitting tensile strength. Also, flexural strength results show that the same replacement rate may even be beneficial to the concrete. Meanwhile, the study also shows that all these properties can be highly impacted by the introduction of even higher PVC contents. Nevertheless, the analysis of the modulus of elasticity tests indicates that the PVC incorporation is particularly deleterious to the performance of the concretes. In fact, an $85 \%$ replacement of fine and coarse aggregate returns a reduction in the modulus of $73 \%$ and $85 \%$, respectively. Moreover, stressstrain relationships for the compositions indicate that the addition of PVC aggregate leads the a more ductile response than when only natural aggregates are used, which the authors justify is due to the elongation displayed by the plastic particles prior to failing. Also, especially in the case of coarse aggregate substitution, as the PVC aggregate content grows, the ultimate fracture strain increases (while the lateral strain, in peak compressive strain, decreases). Additionally, the observation of the concrete's modes of failure indicates that, for the compressive test, the control concretes displayed a typical shear failure. However, when the PVC aggregates 
were added, the number and spacing of cracks was severely decreased (which the authors attribute to the ductile behavior of the PVC). The same exact behavior was observed in the case of the splitting tensile failure, which indicates that the PVC addition affects the mechanical performance both under tension and compression. Finally, weight loss through abrasion tests revealed that both the fine and coarse fraction substitution lead to improvements in the resistance to abrasion. Furthermore, the coarse aggregate substitution leads to higher gains in abrasion resistance (53\% versus a $9 \%$ decrease for the fine replacement). The study justify this fact as being a consequence of the higher energy absorption of the PVC aggregate (thus leading to an increase in plasticity and crack control). Meanwhile, a previous study on the substitution of fine aggregates for scraped PVC pipes in concretes, [73] also detected, despite the use of a naphtalene formaldehyde SP, a workability and density loss, following the PVC addition. Also, compressive and tensile strength were impacted by the aggregate replacement. Furthermore, the modulus of elasticity decreased and the Poisson's ratio improved, thus revealing an increase in ductility of the concretes. The aggregate substitution also caused an upgrade in drying shrinkage and the resistance to chloride ion penetration. The study concludes recommending that the replacement of aggregate for scraped PVC pipes not be performed in structural concretes and that it should only be used to a maximum fine aggregate replacement rate of $15 \%$.

More recently, [74] covered the use of PVC waste (and also high-density polyethylene and polypropylene waste) as fine and coarse aggregates in concrete compositions. The authors made use of a polymer-based superplasticizer optimized according to the plastic content of each sample (as they anticipated the waste addition would induce a loss in workability) and reported a decrease in density of fresh and hardened concrete proportional to the amount of waste aggregate utilized (up to $75 \%$ plastic aggregate in volume). Furthermore, the natural aggregate replacement led to a considerable compressive strength, dynamic modulus of elasticity and ultrasonic pulse velocity loss, and also, an increase in the concretes' ductility. Nevertheless, the investigation also recorded considerable improvements in thermal insulation, in fact, for the concrete containing $75 \%$ PVC waste, a $67 \%$ reduction in thermal conductivity was achieved (the lowest tested value).

\section{Glass wastes}

\subsection{ASR reaction}

Glass waste, which is in its majority constituted by silica, and due mainly to its abundance, is a prime target for re-utilization within concrete compositions. In fact, according to the EUROSTAT online database in waste generation [75], in 2018, the amount of glass wastes generated by the 27 members that now compose EU was of $16.37 \times 10^{6} \mathrm{t}$. Nevertheless, the shape of crushed glass and its diverse chemical constitution does not permit, at least for now, the generalized utilization of this waste as aggregate by the construction industry. Furthermore, one of the most important properties that can hinder the utilization of glass wastes as aggregate is this waste's potential for originating alkali-silica reactions (ASR) in concretes. [76] investigated the reactive potential of this material by studying the expansions observed in mortars possessing crushed glass wastes (from different industrial sources) subjected to a $1 \mathrm{~N} \mathrm{NaOH}$ solution, coupled with an accelerated $80^{\circ} \mathrm{C}$ curing. The investigation used soda-lime glass wastes (SL), uncolored (BS-U) and amber (BS-A) boro-silicate glass, and finally, lead-silicate glass (CR), all of the $0.075-2.00 \mathrm{~mm}$ fraction. In this work, the authors observed that SL mortars showed the lowest expansions, followed by the BS-based compositions and ending with the $\mathrm{CR}$ mortar samples. The $\mathrm{NaOH}$ and saturated lime water solubility tests performed demonstrated that the $\mathrm{CR}$ wastes induced the highest solubility, versus the lowest solubility of the SL glass. Consequently, a direct correlation between the glass solubility and mortar expansions was found. While analyzing the chemical properties of the ASR gel, the researchers found that small differences in the chemical composition of the waste can lead to distinct ASR gel compositions. In particular, the dissolution of $\mathrm{CR}$ (which is governed by a mechanism of dissolution of the homogenous network) is very different to the dissolution through layer detachment observed in all other wastes and can help to explain the worse behavior observed in CR mortars. Furthermore, it can be concluded that the SL and BS wastes' $\mathrm{Ca}_{2}^{+}$ions content can create a buffer effect and prevent the dissolution of the glass.

Meanwhile, [77] studied the role of the glass wastes' pozzolanicity in mitigating ASR phenomena in waste glass mortars For this purpose, the authors performed several tests to mortars containing coarse and fine glass wastes, namely, accelerated expansions, isothermal calorimetry, evaluation of XRD patterns, and also, analysis of the pore solution composition. According to these researchers, the pozzolanic reaction of soda-lime glass consumes portlandite to form $\mathrm{C}-\mathrm{S}-\mathrm{H}$ and, at the same time, contributes to a decrease in monosulfate. Also, the results show that the increase in alkali concentration of the pore solution caused by the glass wastes addition, the increase in Al concentration leads to a reduction in the dissolution of reactive silica, and consequently, minimizes ASR reaction. A more recent study, [78], promoted the pre-treatment of glass soda-lime glass wastes with combinations of calcium and sodium hydroxide, cured for 1, 4 and 7 days at $80^{\circ} \mathrm{C}$ (for the acceleration of the reactions) and was able to mitigate ASR expansions in concretes containing fine glass aggregates. In fact, concretes containing glass wastes and treated with a blend of calcium and sodium hydroxide yielded a 50\% reduction in expansions relative to the reference samples. Furthermore, the study also argues that the pre-treatment of the fine wastes is able to totally reverse the negative effects of a $20 \%$ aggregate replacement in compressive strength.

\subsection{Glass wastes from various sources}

\subsubsection{Wastes from diverse industrial sources}

As to the application of recycled glass wastes as aggregate in concrete [79] studied coarse and fine glass aggregates sourced from building and automobile windows and found that the density, water absorption and abrasion resistance of the wastes were all lower than those of natural aggregates. Furthermore, the high shape index possessed by the waste suggests that, although this property is highly dependent of the original shape of the glass, these particles are of an elongated nature. The investigation further states that, while for concrete containing the fine aggregates substitution, the workability of the concretes decreases, while the opposite happens when the coarse fraction of the aggregates is replaced. Furthermore, a strong downgrade in the concrete's density and a moderate loss in 28-day compressive strength was also found while small substitution rates (up to $10 \%$ ) of either fine or coarse (or both) aggregates led to a decrease in water absorption by capillarity. As to water absorption by immersion, the aggregate replacement was not found to promote an increase in this property. Moreover, the 56-day carbonation resistance was also improved (contrary to the results observed for short-term curing periods) and the resistance to chloride penetration decreased. In relation to shrinkage, this concrete displayed a similar behavior to the one demonstrated by the reference concrete being that the simultaneous addition of coarse and fine glass waste led to a better performance. 
Further information regarding the replacement of natural aggregates for glass wastes sourced from the construction industry can be found in the section dedicated to construction and demolition waste Meanwhile,[80] studied the use of coarse aggregates sourced from industrial car windshield glass wastes in selfcompacting concrete compositions. The researchers also made use of a superplasticizer, marble wastes (as filler material), and also, experimented with different combinations of fine and coarse recycled aggregates from construction and demolition waste. The results showed that the workability of the concretes is impacted by the glass aggregates. Nevertheless, the authors found that the yield stress and plastic viscosity of the concretes are within the range normally displayed by self-compacting concretes (although segregation ratios of these compositions indicate increased viscosity, and therefore, of blockage risk). The study also shows that the compressive strength of concretes containing full replacement of coarse natural aggregates for glass wastes is considerably decreased, when compared to reference samples.

\subsubsection{Soda-lime bottles wastes}

Soda-lime bottles are a major contributor to the worldwide municipal solid wastes generation. While there are, nowadays, adequate recycling processes implemented for most SL glass wastes, these can generally not be enforced when the waste is not conveniently sorted. More specifically, if wastes from bottles of different colors (and therefore different chemical compositions) are mixed, the recycling of the glass into a commercially viable glass product is, for the large majority of applications, virtually impossible. Furthermore, the morphology of crushed SL glass waste particles (Fig. 6) is considerably distinct to that of natural aggregates. [81] studied the replacement of natural aggregates for recycled SL wastes in concretes (containing fly ash as an ASR mitigation measure) having found that the workability of the mixtures was not meaningfully impacted by the addition of the waste. Moreover, density, compressive and splitting tensile strength, and also, the elasticity modulus were all found to be negatively correlated with the rate of aggregate substitution (although a $45 \%$ aggregate substitution rate yielded a decrease of less than $15 \%$ in all the mentioned properties). With respect to the resistance to chloride ion penetration and drying shrinkage, the results showed that the addition of glass wastes was slightly beneficial to the concretes. Finally, the study of ASR expansions in mortars showed that, although the sample containing $45 \%$ recycled aggregate displayed serious expansions and cracks at 28 days curing, the inclu-

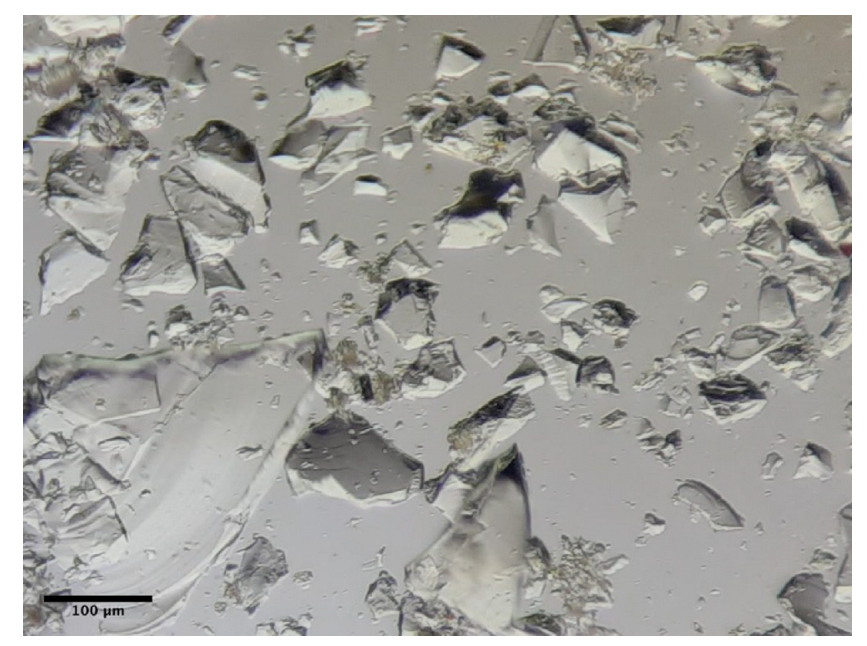

Fig. 6. Optical microscope image, at $10 \times$ magnification, of crushed soda-lime bottles glass with a maximum particle size of $500 \mu \mathrm{m}$. sion of fly ash in the compositions substantially mitigated the magnitude of this occurrence to levels bellow $0.1 \%$ (at the same curing age).

More recently, [82] investigated the partial replacement, in concrete compositions, of natural coarse sand for glass wastes, of the same fraction, sourced from mixed colored crushed soda-lime bottle wastes. The authors found that the use of a superplasticer did not prevent a significant deterioration in workability displayed by the samples containing glass wastes. Furthermore, the researchers argue that the mechanical (compressive, splitting tensile and flexural) strength was not significantly impacted by up to a $60 \%$ replacement of coarse sand, and also, that ASR-related expansions were improved by the same content of glass wastes. These results are in contradiction to the majority of the research available in the field of the utilization of glass wastes in concrete compositions and are seriously by the disparity in workability values observed in the reference sample ( $90 \mathrm{~mm}$ slump) in comparison to the mixtures containing glass wastes (from 40 to $60 \mathrm{~mm}$ slump).

In a different study [83] promoted the replacement of coarse aggregates for soda-lime glass wastes in concrete compositions and focused on the effects of the replacement on the hydrodynamic abrasion resistance of concretes, a property especially relevant for hydraulic structures applications. For this purpose, the authors included silica fumes, polypropylene microfibers and a water reducer to the traditional concrete elements. The inclusion of glass wastes in the concrete was found to negatively influence compressive and splitting tensile strength, which the authors argue is due to the flaky nature of the glass particles. Alternatively, the elastic modulus was not meaningfully affected by the glass inclusion. As to the hydrodynamic abrasion resistance of the concretes, the study found that a coarse aggregate replacement rate of up to $25 \%$ did not significantly reduce its resistance. Also, it was found that the abrasion resistance of a concrete containing coarse limestone aggregates possesses a comparable abrasion resistance to the one displayed by the mentioned $25 \%$ glass wastes concrete.

\subsubsection{Cathode ray tubes wastes}

Electronic waste is becoming an increasingly important problem in modern societies. According a recent EUROSTAT estimate [84], the total e-waste collected in the EU-27 in 2018 was of around $4 \times 10^{6} \mathrm{t}$. Among these wastes, and contrary to the glass wastes already discussed, waste cathode ray tube (CRT) glass contains leachable substances and is classified as an hazardous solid waste. Among the chemical constituents of the waste, the one that poses the highest threat is lead oxide, as CRT glass wastes usually contain $20-25 \%$ of this element by weight. Also, and in opposition to the previously mentioned glass wastes, CRT glass has higher specific gravity than natural aggregates. As to water absorption, and similarly to other glass wastes, $[85,86]$. observed that CRT wastes results are lower than the ones presented by their natural equivalents. Additionally, both studies also found that concrete mixtures suffer a workability loss when CRT glass replaces natural aggregates which, it is argued, may be connected to the angular shape of glass particles (thus creating higher resistance to flow). Furthermore, due to the higher density of CRT glass, it is also reported that the waste addition originates an increase in concrete density and [85] adds that the density increase is higher when replacing coarser fractions of aggregates, according to these researchers, is the result of the improved particle packing originated by these glass particle sizes. As to mechanical performance,[85] report a slight decrease in compressive and splitting tensile strength cause by the CRT addition. The investigation argues that the smooth nature of the glass surface and the lead leachates originated in CRT particles contribute to the weakening of 
the aggregate-binder bond and delay the hydration of cement. On the other hand, [86], using only low substitution rates of finer fractions of CRT waste, observed a slight compressive strength upgrade relative to the control composition. In relation to water absorption by immersion, [85] states that the CRT aggregate's lower water absorption leads to reductions of up to $25 \%$ for the concrete containing full replacement of aggregates for CRT. Additionally, the same study also assessed the elasticity modulus of the concretes reporting that the CRT aggregate addition has a deleterious effect on this property. Moreover, [86] reports that an aggregate replacement rate superior to $10 \%$ leads to deleterious expansions in concrete (ASR reaction) and it is stated that the CRT aggregates used in the study (which possessed an higher than usual concentration of embedded lead) caused a lead leaching which was superior to the statutory limits. Furthermore, the leaching was found to be dependent of the composition's $\mathrm{pH}$ and displayed a decrease over time. Finally, the use of a biopolymer solution for leaching encapsulation in a concrete with a CRT aggregate substitution rate of up to $20 \%$ was shown to originate a decrease in the concrete's lead leaching to below drinking water limits.

Meanwhile, [87] studied the utilization of coarse CRT glass wastes as aggregates in concrete. Moreover, the researchers utilized two methods for obtaining aggregates from CRT waste: the more traditional crushing technique (GC); melting and annealing the waste to produce spherical aggregates (GS). The results of the physical and mechanical tests performed to the glass wastes show that the latter technique leads to lighter, rounder aggregates, with lower water absorption ratio and crushing value. As to the workability of the concretes, the authors found that using both wastes as coarse aggregate, coupled with the utilization of a superplasticizer, improves the workability of the compositions. Moreover, the volume of voids, specially in the case of GS, is increased by the addition of glass wastes. Also, compressive, splitting tensile and flexural strength are considerably negatively affected by the replacement of natural aggregates while water absorption and drying shrinkage are improved by the inclusion of glass wastes. Furthermore, the study showed that the utilization of CRT glass wastes originated increased ASR expansions, when compared to control mixtures. Finally, TCLP tests showed only minimal lead leaching in concrete samples containing GC and GS.

\section{Domestic and municipal}

\subsection{Rubber waste}

\subsubsection{Tires}

Nowadays, a significant share of used rubber tires is either recycled, re-used or employed as fuel in the energy sector, nevertheless, as further detailed, this waste has potential to be utilized as a substitute for natural aggregate in concrete compositions. The most recent data concerning total rubber waste generation in the EU-27[75] indicates, that in 2018 , roughly $4 \times 10^{6}$ t of these wastes had been produced. The shape of tire aggregate (TA) that is obtained after the shredding process has taken place is, usually, similar to the one displayed by natural aggregates, although for the 7-9 $\mathrm{mm}$ fraction, according to [88], this material is significantly rounder than its natural equivalents. Additionally, [88,89] state that, when compared to natural aggregate, shredded tyre waste possesses lower density and higher water absorption. Furthermore, the same authors also detected a workability decrease, originated by the addition of the rubber aggregate, while both agree that rubber aggregates are also the cause for the reduction in the density of concretes. As to mechanical properties, [89] states that the compressive and splitting tensile strengths and the elasticity modulus of the TA concrete decrease proportionally to the con- tent of TA aggregates in the compositions, which is amplified by the replacement of the finer fractions of natural aggregates for TA. In opposition, the study states that the abrasion resistance of the samples improved as a result of the rubber addition (Table 4). Moreover, [88] observed that TA concrete tends to possess higher shrinkage than reference concretes, which is attributed to the higher $w / c$ ratios of these specimens and to the TA's lower capacity to restrict shrinkage (being that finer waste fractions were detected to be more deleterious to the concrete than the coarser particles). Additionally, when compared to the control composition, it was observed that TA concrete experiences greater autogenous shrinkage (from the initial cement hydration appearance onwards). Meanwhile, it is also stated that the concrete's water absorption by immersion is also increased by the presence of TA and a moderately strong correlation $\left(R^{2}=0.86\right)$ between the TA aggregate content (up to a $15 \%$ replacement rate) and water absorption by immersion could be observed. This behavior, the study states, can be due to the higher water content and the void volume of the composition. Also, after having observed (during the concrete's production stage) that longer vibration periods led to concrete segregation, the authors opted to perform short vibration periods to the mixes, which may have lead to less compaction, and thus, higher water absorption. Furthermore, in contrast to their behavior in other parameters, coarser TA fractions originated higher water absorption by immersion, and also, water absorption by capillarity tests were found to be inconclusive as to the influence of the aggregate replacement to this property. As to carbonation depth, the results increased linearly with the TA content $\left(R^{2} \approx 0.90\right)$ which, as the factors influencing this property are the same as the ones determining water absorption by immersion, was an expectable outcome. In fact, the 28 days carbonation depth increased $56 \%$ when $15 \%$ of the coarse aggregate was replaced. Also, both investigations (developed in parallel) assessed the influence of two grounding techniques in the production the aggregates. In the first process, the aggregate was produced by cryogenically cooling rubber particles using liquid nitrogen followed by a hammer crusher. In the second alternative, the tires were simply mechanically grounded to produce smaller sized particles. The results obtained do not support a positive influence in introducing cryogenically cooled rubber particles in the shredding process of TA for the production of concrete.

In a study focused on concrete durability, [90] found that a replacement of up yo 7.5\% fine aggregates for shredded tire rubber wastes of the same fraction in concrete compositions does not impact chloride ion penetration. As to water absorption of acid attacked concrete specimens, the researchers observed that the increase in rubber wastes content was correlated to the increase in water uptake while the contrary effect was detected (upgrade in concrete quality correlated with increase in rubber aggregates content) when measuring weight compressive strength loss resulting from the same acid attack. These results suggest, although more research is needed focusing on the durability properties of these concretes, that the addition of small percentages of tire rubber aggregates may be a suitable practice for designing concrete which will be subjected to aggressive environments.

\subsection{Food waste}

\subsubsection{Mollusk shells}

Among the varied food wastes produced by humans, there are those which, due to their inherent material constitution, can present potential for use as construction material. Such is the case of some types of shells of marine organisms usually found in mollusk shells (MS). These structures, composed of mineralized biological tissue, are the basic material of a type of sedimentary rock 
Table 4

Summary of important TA concrete properties. Adapted from [89].

\begin{tabular}{|c|c|c|c|c|}
\hline \multirow[t]{2}{*}{ Property } & \multicolumn{4}{|c|}{ Aggregate replacement rate (Vol.) } \\
\hline & $0 \%$ & $5 \%$ coarse & $5 \%$ coarse and fine & $5 \%$ fine \\
\hline Compressive strength, 56 days [MPa] & 57.6 & 50.5 & 48.7 & 45.9 \\
\hline Elasticity modulus, 28 days [GPa] & 40.6 & 33.9 & 3.4 & 34.2 \\
\hline Abrasion wear depth, 91 days [mm] & 2.6 & 1.7 & 1.7 & 2.0 \\
\hline
\end{tabular}

(coquina), thus demonstrating their potential for use as aggregate in concrete. Once again the data available concerning to the global generation of "Animal and mixed food waste" (group which includes mollusk shell wastes) in the EU-27 countries during 2018 [75] indicates that around $22.5 \times 10^{6} \mathrm{t}$ of these wastes were generated. Moreover, [91] cites data suggesting that over $15 \times 10^{3} \mathrm{t}$ of scallop fishing was performed in 2013 in the NorthWest region of France.

As stated in [92,91], MS are overwhelmingly composed of calcite/aragonite, with trace amounts of soluble and insoluble organic matrices. Additionally, when crushed, and especially for particles of dimensions inferior to $1 \mathrm{~mm}$, they assume a flat and needle shaped form, with a high flakiness index and an undesirable particle size distribution. Therefore, special care must be taken when using this material as aggregate in concrete mixtures and ideally, the utilization of the finer grains of the crushed waste must be avoided (as these will originate the need for higher contents of binder). Also, the shells must be subjected to a simple water cleaning process, mainly to remove adhered dirt, organic matter and part of the sea salt content (Table 5). Although addressing different types of seashells (Peruvian scallop valve versus queen scallop shells), both investigations reported that the crushed MS present a slightly different density than natural aggregates and higher water absorption. Moreover, [92] states that the chloride ion and sulfate content were both situated within regulatory limits for aggregates in OPC concretes [93], however, it was also observed that the total content of salts exceeded the same limits. As to the properties of the fresh and hardened paste, [91] reports that, as the shell content is increased, the particle packing density and entrapped air rise. Also, [92] confirms the increased air content and adds that the unit weight of concrete samples, especially for higher w/c ratios, is similarly affected by the aggregate replacement. In addition, both authors agree that the workability of the mixtures was moderately reduced by the waste addition. Moreover, when investigating the mechanical properties of the hardened concrete, the mentioned studies found that the sand replacement originates a compressive strength decrease, however, the magnitude of the strength decrease observed by the investigations is considerably distinct as [92] describes a 28-day compressive strength reduction of less than $10 \%$ for a $60 \%$ aggregate replacement, while [91] observed a $20 \%$ decrease for the same replacement rate. In contrast, the researchers agree that splitting tensile strength is only slightly

Table 5

Properties of fine natural aggregates and crushed mollusk shells. Adapted from [92].

\begin{tabular}{lll}
\hline Property & River sand & Crushed seashell \\
\hline Maximum particle size [mm] & 4.76 & 4.76 \\
Fineness modulus & 2.22 & 4.57 \\
Loose unit weight [g/cm3] & 1.410 & 1.015 \\
Rodded unit weight [g/cm3] & 1.584 & 1.224 \\
Specific gravity & 2.53 & 2.57 \\
Absorption [\%] & 1.01 & 1.88 \\
Water content [\%] & 0.57 & 0.30 \\
Organic matter content [\%] & - & 1.03 \\
Chloride ion content [\%] & 0.0039 & 0.0139 \\
Sulfate content [\%] & 0.0073 & 0.0146 \\
Total salts content [\%] & 0.0206 & 0.0656 \\
\hline
\end{tabular}

affected by the aggregate replacement which, it is argued, is a proof that the adherence of the waste particles to the cement paste is similar to that of the natural aggregates. In relation to durability properties, which were addressed in [91], the natural aggregate replacement originated the increase in the chloride diffusion coefficient and the water accessible pores. This result is taken, by the authors, to be a sign of the non-uniform compactation of the concrete mixtures. Therefore, the investigation recommends the introduction of needle vibration and the application of an extended period of vacuum curing (in order to increase the effectiveness of the specimens' water saturation). Finally, it is reported that, likely as a result of the increase in the $\mathrm{w} / \mathrm{c}$ ratio, as the shells content was risen, the depth of the water penetration in concrete also increased.

In a recent study, [94], studied concretes in which the fine fraction of the aggregates was partially replaced by crushed Scallop seashells and cement was also substituted, in part, by rice husk ash (RHA). Since no water reducing agents were used, a workability degradation caused by the waste aggregates' addition was to be expected, and thus, the results show that the increase in waste aggregates implied a corresponding loss to the concrete's workability. Furthermore, compressive, splitting tensile, and flexural strength were all also negatively impacted by the addition of seashells. Nevertheless, a combined fine aggregate and cement replacement (of up to $20 \%$ content each) by the seashells and ash, respectively, resulted in an improvement of the same mechanical strength properties.

\section{Wastes originated by the construction industry}

Construction and demolition waste recycling is one of the most promising sources of material with potential to, at least partially, replace natural aggregates in concrete mixes. One of the most important reasons for this fact is the availability of this material. In fact, according to the already mentioned EUROSTAT dataset concerning the total waste generation of EU-27 countries in 2018 [75], mineral waste from CDW production for the same year and region was of almost $300 \times 10^{6} \mathrm{t}$ (or approximately $13 \%$ of total waste produced). The end quality of the recycled waste is, nevertheless, largely dependent on the properties of the original materials, their state of decay and the removal/demolition approach selected to recycle them. Also, the use of these aggregates, regardless of the potential environmental benefits that this practice may originate, is always associated with some type of compromise in other properties of the concrete.

\subsection{Construction and demolition waste}

\subsubsection{Recycled concrete aggregates}

One of the most thoroughly researched materials for use as a substitute to natural aggregates in concrete is crushed structural OPC concrete. Usually, the final version of the processed waste is obtained by removing the reinforced steel from the old concrete, and afterwards, crushing the remaining material to a granular fraction. This material, generally referred to as recycled concrete aggregate (RCA), has been extensively studied in scientific research 
for natural aggregate substitution and is currently considered, by numerous national regulations and standards of practice (and within strict limits) already considered to be a viable concrete material. The current European regulation on the matter is [31], whereas the composition of the concretes is tested according to EN 933-11. According to this last document, to be considered RCA, the final processed waste must be composed of at least $90 \%$, in weight, of Portland cement-based fragments and natural aggregates.

Although the constitution of the waste is of great importance, the manner in which it was obtained is not, in any way, less relevant. In fact, [95] used two distinct processing cycles to the same old concrete and observed that properties like shape, water absorption or saturated surface dry density yielded different results for each of the aggregates. More specifically, the first recycling process produced fine and coarse aggregates while the second approach only returned fine aggregates (by repeatedly crushing the coarser waste). The results show that the additional crushing of the coarse aggregates provided for a smoother and rounder fine aggregate, with lower water absorption and greater saturated surface dry density than when crushing and screening the coarser fraction to obtain comparable fine aggregates. Furthermore, the existing literature is clear in attributing lower performance to the concrete containing fine RCA, when comparing to the coarser fraction. In fact, as stated in [96], higher cement content, increased porosity, water absorption and sulfur compounds all contribute to the downgrade in quality of the fine RCA concretes. Nevertheless, when compared to natural aggregates, all types of RCA typically display worse performance in physical and morphological attributes.

As to the qualities of the concrete compositions that include this waste, it is first important to address the impacts of the addition of recycled RCA to the characteristics of the concrete's region situated between the aggregates and the cement paste (known as interfacial transitional zone, or ITZ) as it is critical for the development of high performance concrete [97]. The utilization of aggregates containing cementitious materials bound to the old aggregate leads to the creation of multiple ITZ's within the microstructure of the new concrete. Therefore, it is only natural that the multiplication of ITZ layers in concrete containing these aggregates causes, as detailed below, the degradation of the properties of the respective compositions (Fig. 7).

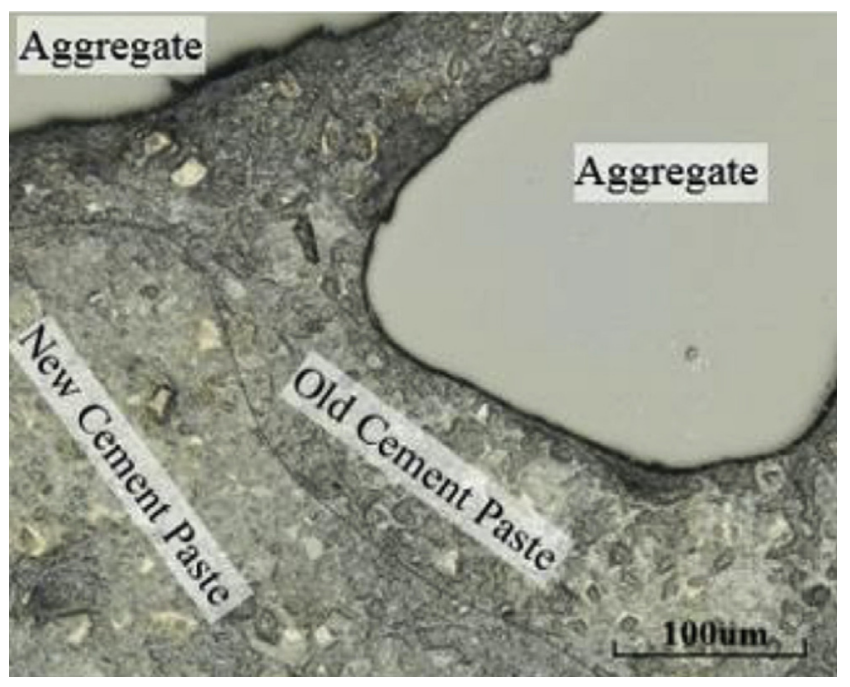

Fig. 7. Laser scanning microscope (LSM) detail of the creation of a second ITZ layer in concrete containing RCA [98].
In fact, as expected from the previously mentioned RCA properties (especially the rough and angular nature of these aggregates), workability results are typically lower than when only natural aggregates are used and in case appropriate measures are not taken to overcome this situation, the concretes usually possess lower strength and durability when compared to their equivalents produced with natural aggregates. In fact, the higher hydration needs of these concretes lead to increased $\mathrm{w} / \mathrm{c}$ ratios, and consequently, the quality of the concretes will be lower.

To tackle these issues, superplasticizers or mineral admixtures have proven to be effective in lowering the hydration needs of these mixtures and therefore mitigate the negative effects of RCA additions. As an example, while these concretes have been shown to possess lower densities, as stated in [95], other authors managed to minimize the density reduction introduced by the presence of fine and coarse RCA by adding either lignosulfate or polycarboxylic superplasticizers to the mixtures $[99,100]$. Meanwhile the same authors also reveal that, especially when using a polycarboxylic SP, and even for a full aggregate replacement, the compressive strength of the concretes is not meaningfully downgraded by the fine RCA and is not impacted whatsoever by the coarse aggregate replacement (Table 6). However, when SP's are not used, as is the case in [95], the results tend to show a reduction in compressive strength. Additionally, and although these wastes contain far less amounts of contaminants (such as wood, asphalt, glass and plastic, among others) than other recycled aggregates also reviewed in this section, even a low presence (of less than $1 \%$ ) of aluminium, which is an element that can frequently be found in these wastes (as it is extremely difficult to screen), is deleterious to the concrete performance as it leads to a significant loss in the concrete's compressive strength (Fig. 8).

Another possible mitigation measure is the introduction of mineral admixtures to the concrete mix. [102] added fly ash to the mixtures and reported that the full replacement of the coarse aggregates and the simultaneous replacement of up to $35 \%$ of cement for fly ash caused a slight upgrade in the long term (10 year) compressive strength. Moreover,[100] states that the use of SP's does not totally mitigate the splitting tensile strength loss from the coarse recycled aggregate's addition. In reality, the authors suggest that the mortar content of the aggregates is one of the main factors influencing this outcome, as it decreases the density and, therefore, the splitting tensile strength of the concrete. Nevertheless, the polycarboxylate SP, once again, performed better than the lignosulfate SP. Meanwhile, [102] state that, although for shorter curing periods RCA seems to be detrimental to splitting tensile strength, for a 10 year curing period and even if no mineral admixtures are introduced, the full coarse aggregate replacement is slightly beneficial. As to the elasticity modulus, the authors found that the aggregate replacement induces a reduction to this property. Furthermore, regarding the durability properties of RCA concretes, $[99,95]$ agree that water absorption by capillarity is higher than in standard concrete, which was an expected result, as this type of water absorption is mainly determined by the porosity of concrete. Additionally, the studies state that, although polycarboxylate SP is the most effective in reducing the water

Table 6

Selection of RCA concrete properties. Adapted from[100].

\begin{tabular}{llc}
\hline Property & \multicolumn{2}{l}{$\begin{array}{l}\text { Coarse aggregate } \\
\text { replacement rate (Wt. }\end{array}$} \\
\cline { 2 - 3 } & $0 \%$ & $100 \%$ \\
\hline Workability [mm] & 85 & 78 \\
Compressive strength, 28 days [MPa] & 49 & 49 \\
Abrasion wear depth [mm] & 0.29 & 0.21 \\
\hline
\end{tabular}




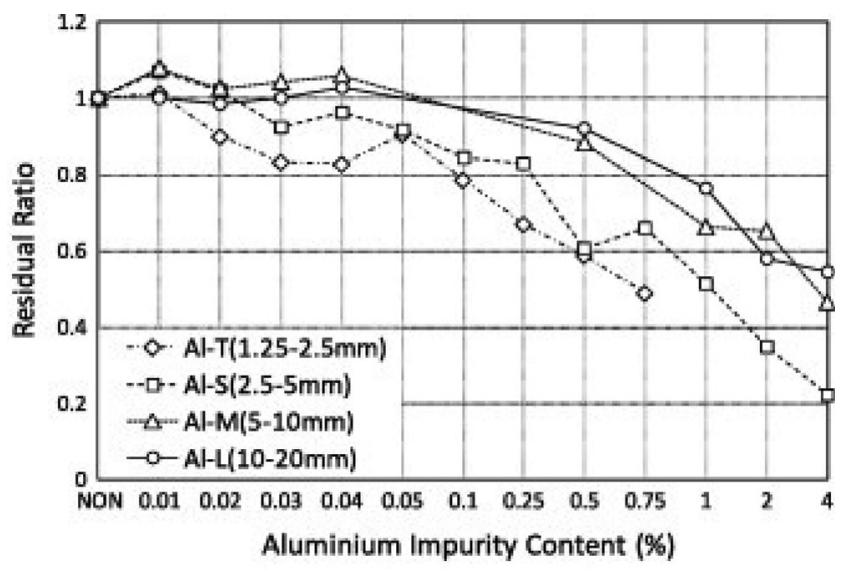

Fig. 8. Residual compressive strength ratio of concrete samples according to their impurity content [101].

absorption increase of the samples, it is also the more susceptible to the micro structural changes introduced by the aggregate. Moreover, while studying water absorption by immersion in RCA concretes containing SP's, [99] state that this property increased linearly with the growth in RCA content (which possesses higher porosity). Also, the polycarboxylates SP was more effective in reducing water intake, as it achieved a mean water absorption by immersion reduction of roughly $40 \%$ (versus about $25 \%$ of the other $\mathrm{SP})$. On the other hand, carbonation resistance and chloride penetration testing demonstrated that this property is impacted by the RCA addition. Nevertheless, the utilization of SP's, especially in the case of the polycarboxylate version, can mitigate the effects of the aggregate replacement. Simultaneously, [102] also agrees that the carbonation resistance decreases with the addition of RCA. In respect to the abrasion resistance of the concretes containing coarse RCA addressed in [100], the results show that the higher absorption capacity and roughness of the coarse recycled aggregates lead to the observed higher resistance values, suggesting that SP's have no influence on this property. Finally, [95] also shows that the RCA concrete's ultrasonic pulse velocity and electrical resistivity both decrease and the initial surface absorption is higher. In conclusion, there are, presently, several practical examples of RCA utilization in structural concrete [103]. As far as is known, these concretes are totally able to fulfill the mechanical strength requirements of structural concrete. Furthermore, and although these constructions are all relatively recent, significant durability issues have not been detected thus far.

\subsubsection{Recycled masonry aggregate}

Another major family of materials thoroughly used in construction, particularly in the residential sector, is masonry. As a consequence, high amounts of waste are involved in the utilization, production and disposal of this material. If correct recycling procedures are implemented, considerable amounts of uncontaminated masonry can be obtained from CDW. This waste is designated as Recycled Masonry Aggregate (RMA) in [31] and is defined as being composed (in at least $90 \%$ by mass) of masonry unit and nonfloating concrete wastes. As to the properties of the processed material [104], which used crushed red bricks aggregates in concrete compositions, state that the finer fraction possesses lower density when compared to fine natural aggregates, while the inverse situation is true for the coarser fraction. Meanwhile, [105], which limited the coarser fraction of red brick waste to $12 \%$ of the aggregates' weight, reports that the RMA used in the investigation had a lower density than the one displayed by natural aggregate. All the mentioned authors agree that, compared to natural aggregates, RMA possesses higher water absorption values. As to the morphology of the waste, [106] shows that the grains contain pores of irregular and heterogeneous sizes (Fig. 9). In relation to the properties of the fresh paste, [105] assessed the occluded air of the RMA concretes and concluded that this property increased in tandem with the rise in RMA content. Furthermore, and citing Spanish regulations, the authors observed that, up to a $70 \%$ waste substitution (in aggregate volume), the concrete specimens possess an occluded air content in the range of $4.5 \%$ to $6 \%$, and thus, perform within the limits established by the said legislation. Additionally, as loss in workability is to be expected in concretes containing RMA, $[105,104]$ chose to optimize the design of the concretes in order to yield roughly the same slump results without the need for superplasticizer additions. The density tests performed revealed that the waste addition induces a reduction in this property. In fact, according to the relevant European standard [68], the concrete containing a total natural aggregate replacement does fall under the category "lightweight concrete". Additionally, [104] reported observing concrete segregation in the compositions' production stage, and thus, implemented the de-moulding of the samples only after a $56 \mathrm{~h}$ curing period. Regarding the influence of the RMA addition to the mechanical attributes of the compositions, the mentioned authors agree that the elasticity modulus, and also the compressive, flexural and splitting tensile strengths are all negatively affected by the natural aggregate replacement. Nevertheless, [105] found that the compositions with $100 \%$ RMA, which displayed an average compressive strength of nearly $44 \mathrm{MPa}$, would still be able to fit the C30/37 category. Moreover, the assessment, by both investigations, of the durability properties of the RMA concretes revealed that water absorption of these specimens is higher than in normal concretes. Also, [104] states that permeability and shrinkage are increased by the addition of RMA. Finally, [105] also tested the ultrasonic pulse velocity (UPV) of the concretes, a property which is useful for assessing the elastic properties of the aggregates (and thus, the quality of this material) and the results show that the addition of the waste is detrimental to the concrete quality. More specifically, for a total replacement of natural aggregates, the reduction of the concrete's UPV values reached a total of $24 \%$, which, together with the previous conclusions of both investigations is sufficient to

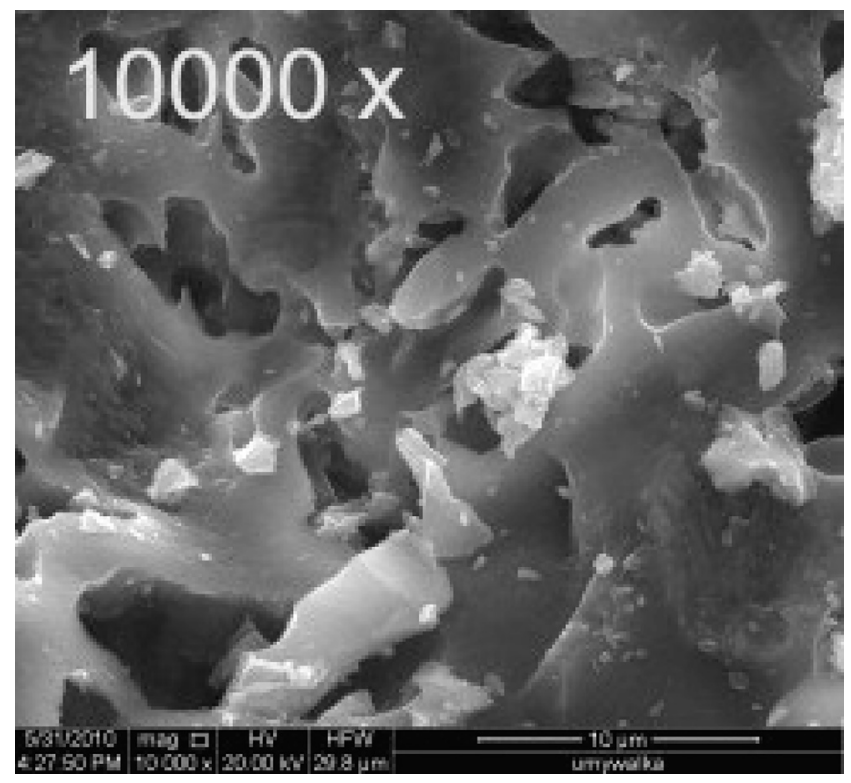

Fig. 9. SEM image, at $\times 10000$ magnification, of a ceramic sanitary waste particle where the irregularity of its pore structure can be observed [106]. 
determine that this concrete would not be suitable for structural applications.

\subsubsection{Mixed recycled aggregates}

In a large number of practical situations, depending on the recycling procedure employed, the available CDW will consist of a mixture of both RCA and RMA. The existing literature usually designates this waste as mixed recycled aggregates (MRA) and what follows is the review of three investigations concerning concrete possessing fine, coarse and fine plus coarse MRA. In the first study, [107] investigated the addition of MRA (sourced from a demolished masonry structure) as partial to full fine aggregate substitution in concrete compositions. The study found that, when compared to fine natural aggregates, MRA presented lower density and increased porosity, crush index, saturated surface dry absorption and sulfates content. In relation to the concrete compositions, and in order to achieve a constant workability value, the authors used polycarboxylate superplasticizer, and also, the water content was calibrated to accommodate the differences in water absorption of each aggregate mixture. Additionally, the recycled aggregates were either used in partial or fully saturated surface dried condition. As to the results obtained, the density tests performed to the concrete samples revealed that this property is slightly affected by the MRA addition and a linear decreasing trend can be observed when plotting the replacement ratio versus both, oven-dry or saturated density with the authors attributing this outcome to the increased porosity, lower density and higher water content of these compositions. As to the mechanical properties of the concretes, the aggregate replacement did not (meaningfully) impact compressive strength, while for splitting tensile strength a clear pattern for the response of the concrete to a growing MRA incorporation did not emerge. Modulus of elasticity tests, on the other hand, show that this property is susceptible to the aggregate replacement. In particular, the full replacement of fine aggregates and saturated aggregates caused a modulus of elasticity loss of $20 \%$ at 90 days curing age. Moreover, the analysis of the pore structure performed through mercury intrusion apparatus (MIP) tests confirms the significant increase in pores possessing a diameter superior to $100 \mathrm{~nm}$, which, according to the authors, play a predominant role in the reduction of the elastic modulus of concrete. Nevertheless, the replacement of natural aggregates for up to $50 \%$ in MRA dry aggregates resulted in no variation in the elastic modulus, thus suggesting that the improvements in the aggregatebinder matrix were sufficient to balance the higher porous nature of the MRA.

In relation to the replacement of the coarse fraction of the aggregates by RMA, [108], using mixed aggregates sourced from a recycling plant and composed mainly of material from [31] Ra and Rc categories (Fig. 10), and while maintaining a constant effective $\mathrm{w} / \mathrm{c}$ ration and using a polycarboxylate superplasticizer found that this aggregate, when compared to equivalent natural aggregate, displays a lower saturated surface dried density and flakiness index, and higher sulfate (and acid-soluble sulfate) content, water absorption and Los Angeles coefficient. Also, when performing the concrete mixes, and as the MRA content increased, the authors observed that the workability and air content of the paste increased and the density decreased. In fact, for a total aggregate replacement, the air content increased by $37 \%$ and the density displayed a $7 \%$ reduction in relation to the control concrete. Furthermore, compressive strength results revealed a negligible reduction in compositions containing up to 50\% MRA and a slight decrease (7\%) for the full natural aggregate replacement. Additionally, despite the fact that the full aggregate replacement resulted in the maximum splitting tensile strength loss (4\%) in relation to the control concrete, strength values did not follow a specific trend in relation to the waste content addition. However, flexural

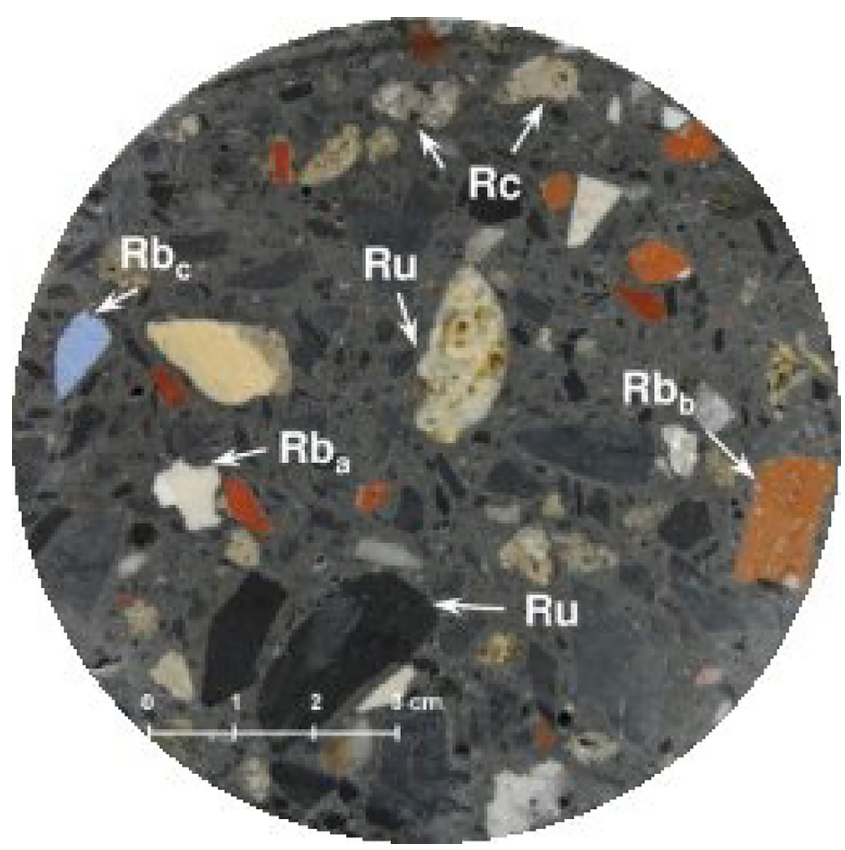

Fig. 10. Image of the cross section of a cylindrical coarse MRA concrete sample in which the several fractions of the waste are indicated as: $\mathrm{Rn}$ - natural aggregate, $\mathrm{Ru}$ - unbound aggregate, Rba - sanitary ware waste, Rbb - crushed brick, Rbc crushed roof tile, and Rc - concrete aggregate [108].

strength values also showed a decreasing trend when the MRA content was increased. Nevertheless, only replacement rates superior to $50 \%$ led to significant losses (with a maximum of $19 \%$ loss corresponding to a $100 \%$ substitution). Furthermore, the investigation performed a morphological analysis to the specimens reporting that the materials were uniformly distributed across the samples, hence indicating no segregation had taken place. The authors also state that the good performance achieved was the consequence of a tight bond existing between the masonry, concrete and unbound aggregate. One final mention is necessary regarding the statistical analysis performed in the study. In fact, the results suggest that all the concrete's properties can be fitted in a normal distribution. Additionally, Shapiro-Wilk p-values also indicate that, except for splitting tensile strength, the evolution of all other properties may be explained by the factor "aggregate replacement ratio".

In another study focusing on the topic of MRA, [109] investigated the performance of concrete containing fine and coarse MRA sourced from a recycling plant having noticed that, regardless of the introduction of superplasticizers, the concrete's workability was negatively impacted by the aggregate replacement. Furthermore, compressive, flexural and flexural strengths all displayed a reduction as the MRA content increased. Additionally, the authors state that the results of the Los Angeles abrasion resistance, absorption index, total sulphate and acid-soluble sulphates tests performed on the aggregates, show that this waste does not meet the Spanish limits established for concrete aggregates. The study also found that using commercial cements containing SCM's can mitigate the negative effects of the utilization of the aggregates in the production of low strength concretes.

Meanwhile, another group of researchers [110] studied concretes based on a binder containing a sulfate resistant blast furnace slag (CEM III/A), plus a blend of Portland cement and clay brick powder. Furthermore, coarse MRA was also added as partial natural aggregates substitution. Also, water additions were calculated considering the effects of real and effective $\mathrm{W} / \mathrm{C}$ ratios and no water reducing agents were utilized. The resulting mixes results 
suggest that a satisfactory concrete workability can be achieved (although this can still be improved through the use of superplasticizers). Moreover, slight density reductions can be observed in the MRA concretes, which may be mainly due to the ceramic fraction of the wastes, while 28-day compressive strength values were not affected by the presence of the waste. Moreover, for pore sizes lower than $10 \mu \mathrm{m}$, the pore structure was refined and porosity results were not impacted by the ceramic content of the concretes. Finally, the observation of the ITZ revealed that, similarly to what can be observed in standard OPC concretes, strong and continuous bonds were present between the cement paste and the recycled aggregates.

In another investigation, [111], the authors assessed the porosity of the ITZ's of a concrete containing MRA. In this research, the porosity of the ITZ was measured through SEM image analysis and the chemical elements were mapped through a SEM-EDS detector and the MIP technique was for contrast. The results show that the MRA addition leads to a $190 \%$ increase in the porosity of the ITZ, in relation to the reference concrete, being that the inclusion of silica fumes considerably mitigates this phenomenon (32\% decrease when compared with the concrete with MRA) as this material acts as filler material within the ITZ pores.

Nevertheless, when the processed waste still contains deleterious adhered materials, one possible solution is to remove these substances through a stage of mechanical crushing. This is often the case when assessing the potential utilization of Recycled concrete aggregates (RCA). Regardless of the high potential for utilization as concrete aggregate that this material displays (especially for coarser fractions), the natural coarse aggregates present in the waste are often encapsulated (at least partially) by a layer of old OPC mortar. As already discussed, this last material is more porous than natural aggregates and originates a reduction in the aggregate's quality. Furthermore, the bond between the old mortar and the natural aggregate, in the area designated Interfacial Transitional Zone (ITZ), is also weak, and is often the reason for the failure of concrete specimens containing RCA. The main methods present in the literature for the removal of old mortar in RCA and which can provide high quality aggregates are the simple crushing and ball milling the waste, which may previously have been heated, thus facilitating the removal of the mortar. Alternatively, the adhered mortar can be removed by the implementation of a soaking treatment, either in water or acid, to RCA. The research states that water exposure may only contribute to the removal of looser mortar. In relation to the acid treatment, the use of hydrochloric, sulfuric and phosphoric acid for $24 \mathrm{~h}$ can contribute to the dissolution of the cement hydration products. Nevertheless, this procedure increases the cost of the concrete production, its chloride and sulfates content and has the potential to substantially decrease the $\mathrm{pH}$ of the mixture. Other currently available enhancement strategies for concrete containing recycled aggregates include [112] the use of water reducing agents, the addition of nano-silica or pozzolanic materials (fly ash, steel slags, amongst others), soaking the aggregate in a sodium silicate solution and the instigation of calcium carbonate reaction products through bacterial biodeposition and carbon hydroxide exposure (carbonation).

In relation to both: concretes containing MRA, and also, strategies for the enhancement of the properties of recycled aggregates, [113] implemented the surface treatment of MRA sourced from a CDW plant with a polymer solution (emulsified acrylic resin), and then, studied the impact of the full replacement of coarse natural aggregates by the treated (and the untreated) aggregates in concrete compositions. While studying the physical properties of the treated aggregates, the authors found that soaking the MRA in a $20 \%$ solution for 60 min yielded the best results and led to a $25 \%$ decline in water absorption and $31 \%$ decrease in the Los Ange- les coefficient (the upgrade in the properties was also confirmed by a two-way statistical analysis). Furthermore, either treated or untreated, MRA presence did not impact compressive strength, and slightly improved splitting tensile strength. Also, results from electric resistivity, UPV and water penetration tests all indicate that the concretes containing the enhanced aggregates may be suitable even for the most aggressive environmental exposure classes. Finally, the researchers also argue that the utilization of untreated MRA in concrete compositions enables a $6 \%$ reduction in mix manufacture, while the treatment of the aggregates leads to an estimated $17 \%$ rise in the same costs. Nevertheless, it is also highlighted the environmental and durability benefits provided by the enhancement of MRA.

\subsubsection{Construction and demolition recycled aggregates}

The study of the behavior of recycled aggregates possessing a higher degree of material variability is of extreme importance to the practical utilization of these wastes in concrete production. Often, the recycled aggregates production processes waste that is constituted, not only of masonry or cementitious products, but also materials like wood, plastic or asphalt, among others. Although an official designation for these recycled aggregates does not exist, in this review, and similarly to other existing literature on this subject, this waste will be designated as construction and demolition recycled aggregates (CDRA). This group of wastes encompasses a wide range of aggregates, and its common thread is, as previously mentioned, the presence of non-standard recycled aggregates materials, such as glass or wood. Current regulation is still very restrictive in what concerns the use of CDRA in structural concretes. In Portugal, for example, there is legislation (E 471-2009 [114]) provided by the National Laboratory for Civil Engineering (LNEC) which prohibits the use of fine CDRA and seriously restricts, using the classification for the classes of recycled aggregates present in the European standard for construction aggregates [31], the utilization of the coarse fraction of the waste (to a maximum of $20-25 \%$ of total aggregate). The recycling processes and waste origin of the recycling facilities can generate aggregates displaying heterogenous compositions. In fact, [115] studied the utilization of aggregates sourced from an Italian recycling plant, which were composed of old concrete (70\% in weight), bricks (27\%) and wastes of miscellaneous nature (3\%). In turn, a group of Portuguese researchers published a set of studies [116-118] in which they also focused on the utilization of aggregate sourced from several recycling plants in concrete and the analysis of the waste's composition revealed that $68.8-85.6 \%$ of the weight comprises concrete, mortar and sand, followed by a $0.9-28.6 \%$ content of clay materials, $0.2-$ $15.4 \%$ of glass, $0.0-10.5 \%$ of bituminous materials and $0.0-2.0 \%$ of other constituents. As to the physical properties of the aggregates, the researchers agree that, when comparing to their natural counterpart, the density is lower and the water absorption is higher in both fine and coarse CDRA. Additionally, [117] also found that, for coarse CDRA, the shape index and the LA wear coefficient are both higher than the ones observed in natural aggregates. The same investigation also performed a set of tests to the waste with the purpose of assessing important chemical properties of the materials. The results of the tests show that the aggregates tend to possess a substantial content in light contaminants (which can reach almost $2 \%$ of the total weight), and also, the chlorides and sulfates contents can be superior to the maximum permitted by the regulations. Regarding the properties of the fresh paste, the available literature, while making use of optimized $\mathrm{w} / \mathrm{c}$ ratios and superplasticizer dosages, agrees that the workability is reduced by the introduction of CDRA. Moreover, [117] observed that the growth in waste additions caused a linear decrease in concrete density. The same investigation, while testing the mechanical properties of the concretes, found that compressive and splitting tensile 
strength and the elasticity modulus were all impacted, to a varying extent, by the addition of CDRA. In fact, as an example, the compressive strength evolution of the concretes ranged from a $5.2 \%$ decrease for a coarse aggregate sourced from one of the recycling plants to a $44.6 \%$ reduction originated by the replacement of fine aggregates originating from another CDW plant, which is revealing of the variability in the properties of CDRA that can be observed in practical situations due to the different recycling processes and diverse compositions of the original materials. Additionally, one of the conclusions that the authors draw from the results is that the higher presence of clay in the fine fraction of the waste originated lower concrete performance. Nevertheless, [115] states that, while the compressive tensile and bond strength is impacted by the waste addition, the incorporation of fly-ash mitigated the deleterious effect of the recycled aggregate addition. Additionally, the same authors found that all waste-containing samples presented a dynamic elasticity modulus inferior to that of the control concrete and that pull-out strength is not meaningfully influenced by the aggregate replacement. Furthermore, [117] observed that the abrasion resistance of the concretes containing coarse CDRA slightly improved. As to the durability performance of the concretes, the addition of recycled aggregates (particularly those with high clay content) led to a moderate to substantial increase in water absorption (by capillarity and immersion), carbonation depth and of the chloride diffusion coefficient (Table 7). Furthermore, in the 2018 study by the same authors [118], it is stated that the addition of a superplasticizer improves these concretes' properties, especially in relation to carbonation depth and when using low aggregate replacement ratios. Nevertheless, the researchers advise against using CDRA possessing high clay contents and in aggressive chloride environments. These results are not confirmed by [115], in fact, after a one year of air exposure, the compositions containing CDRA, when compared to the control concretes, displayed a considerably higher carbonation and chloride resistance. Finally, both investigations also addressed the shrinkage of CDRA concretes. Once more, the researchers state that the shrinkage of the concretes is negatively influenced by the addition of these aggregates. Nevertheless, [115] state that in situations where shrinkage is restrained and creep effects are not considered, the elastic tensile strength will be similar to that of the reference concretes. This means, according to the authors, that the drying shrinkage parameter may not be of critical importance to the performance of concrete belonging to the same strength class.

In another study making use of aggregates directly sourced from CDW recycling facilities (in this case, three distinct Greek CDW plants), [119] also found that the replacement of natural for coarse CDRA aggregates in concrete compositions leads to a low to moderate decrease in compressive strength although the authors attribute this behavior more to the presence of clay minerals than to the higher water absorption displayed by the CDRA as mixtures containing higher percentages of the said clay minerals yielded lower compressive strengths. Furthermore, durability was also found to be impacted by the CDRA presence as carbonation depths and sorptivity of CDRA concrete also increased. Furthermore, after the 14 th freezing and thawing cycle, the value of the dynamic modulus of elasticity was reduced in 80 to $85 \%$, when compared to the reference sample, in what the researchers suggest is a sign of higher internal damage experienced by CDRA concrete.

Having already discussed the properties of concretes containing CDRA, and as these aggregates may be composed of a wide array of undesirable materials, it is now important to address the properties of these concrete's ITZ's. In their investigation, [120] used nanoindentation tests to determine the elastic modulus and the thickness of the ITZ in CDRA concretes. For determining the elastic modulus in the ITZ, paste and aggregate, the authors defined several nanoindentation regions, organized according to the type of waste present in the sample, namely, recycled concrete, wood, plastic, glass, asphalt and clay-based wastes. The results for the elastic modulus in the ITZ and in the paste can be observed in Fig. 11.

Also, from the analysis of the results of the tests performed to determine the thickness of the ITZ for each waste type, shown in Fig. 12, it becomes clear that the thickness of the ITZ in concretes containing asphalt $(65 \mu \mathrm{m})$, wood $(60 \mu \mathrm{m})$ and recycled concrete $(55 \mu \mathrm{m})$ is higher than in natural aggregate concretes (which is usually inferior to $50 \mu \mathrm{m}$ ). Moreover, the value of the average elasticity modulus of the ITZ is always inferior to the one found in the paste, being that this reduction is especially significant when plastic (29\%), wood (27\%) and glass (24\%) aggregates were utilized.

\section{The alternative approach: alkali-activated binder concretes}

The global adoption of the utilization of recycled wastes as aggregates in OPC concretes for structural applications requires the availability of massive amounts of waste (with physical properties which possess a low degree of variability), the adoption of universal standardized recycling procedures and the implementation of frequent extensive laboratory testing to the properties of the wastes and the respective concretes. On the other hand, the existing (and future) strict statutory limits to the utilization of these wastes also imply further obstacles to the massification of this practice. The drawbacks of the utilization of recycled wastes in structural OPC concrete are mostly related to the strengths and weaknesses of these binders. More specifically, one of the main limitations of OPC concretes is the fact that the compressive strength is strongly dependent of the packing of the aggregates [121]. As such, a higher heterogeneity of the particles' morphology (which is frequent in recycled wastes) negatively impacts the compressive strength results of the concretes. Furthermore, and depending on the type of recycled waste utilized, the addition of contaminants (material often present in construction and demolition waste) was shown to negatively influence the quality of the concrete's ITZ.

Table 7

Mean values of several properties of CDRA concrete produced with aggregate obtained from four Portuguese waste recycling plants. Adapted from [116-118].

\begin{tabular}{|c|c|c|c|c|}
\hline \multirow[t]{2}{*}{ Property } & \multicolumn{4}{|c|}{ Aggregate replacement rate (Vol. } \\
\hline & $0 \%$ & $10 \%$ & $25 \%$ & $100 \%$ \\
\hline Compressive strength, 28 days [MPa] & 75.4 & 72.3 & 63.7 & 48.9 \\
\hline Water absorption by immersion [\%] & 10.4 & 9.6 & 10.7 & 15.3 \\
\hline 72-h water absorption by capillarity $\left[\mathrm{g} / \mathrm{mm}^{2}\right]$ & $1.34 \times 10^{-3}$ & $1.27 \times 10^{-3}$ & $1.40 \times 10^{-3}$ & $2.02 \times 10^{-3}$ \\
\hline 91 day carbonation [mm] & 3.6 & 4.9 & 7.1 & 11.5 \\
\hline Rapid chloride migration $\left[\mathrm{m}^{2} / \mathrm{s}\right]$ & $10.1 \times 10^{-12}$ & $13.0 \times 10^{-12}$ & $13.7 \times 10^{-12}$ & $17.5 \times 10^{-12}$ \\
\hline 91 day shrinkage $[\mathrm{m} / \mathrm{m}]$ & $-2.60 \times 10^{-4}$ & $-2.60 \times 10^{-4}$ & $-3.45 \times 10^{-4}$ & $-2.60 \times 10^{-4}$ \\
\hline
\end{tabular}




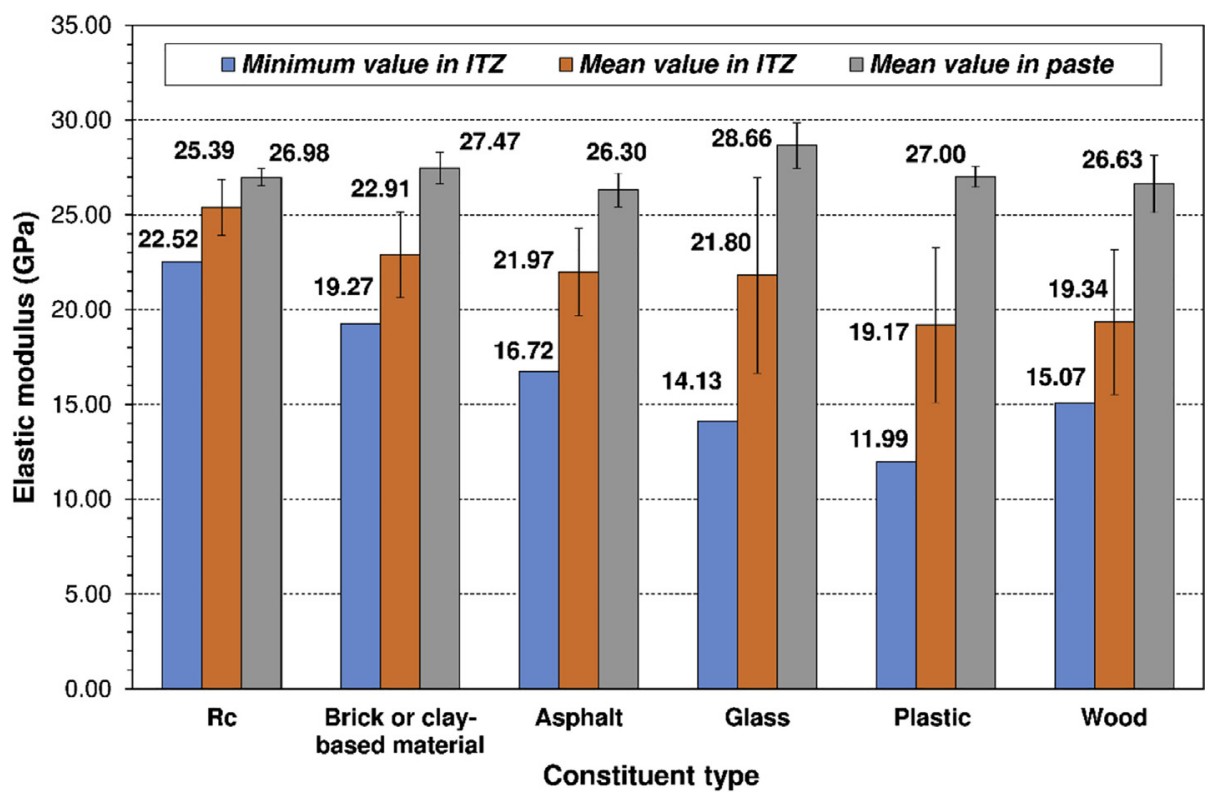

Fig. 11. Minimum and mean elastic modulus in the ITZ and in the paste [120].

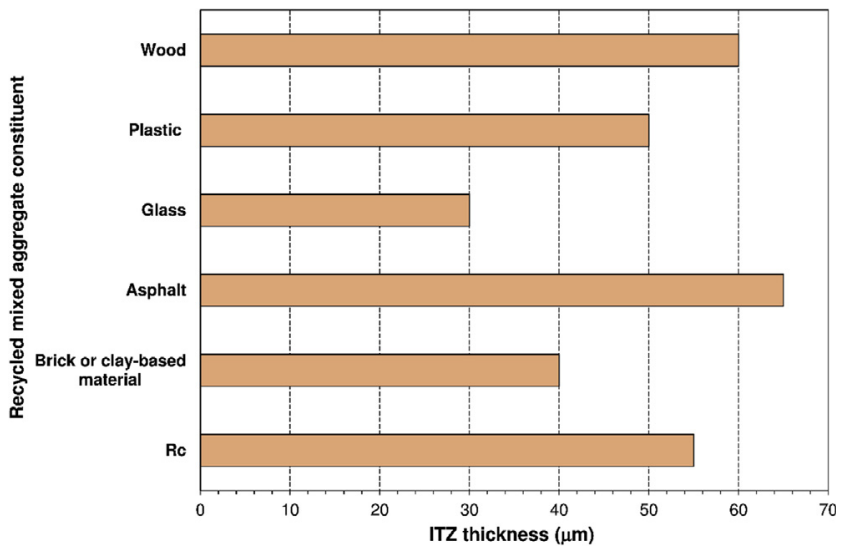

Fig. 12. Thickness of the ITZ for each type of waste [120].

On the other hand, there is another class of binders which offers additional recycling options to a wider variety of wastes: akaliactivated binders. By the nature of their constitution, which is based in a reaction of activation between a material rich in silica and alumina and an alkaline solution, these materials offer the added possibly of the utilization of a binder which is mainly composed of alumina and silica-rich materials. Furthermore, in relation to compressive strength, as compressive strength relies, in AABbased concretes, mainly on the characteristics of the matrix, these compositions are not as impacted by the presence of impurities as OPC concretes are [121], and also, demonstrate the ability to merge new and old ITZ's into a new, albeit still poorly understood, phase [98] (further avoiding the multiplication of these problematic regions). Moreover, these concretes tend to possess higher mechanical strength (for the same water/binder ratio), superior resistance to acid attack and lower susceptibility to ASR, and finally, demonstrate a better capacity for immobilizing hazardous materials [121]. Additionally, there is nowadays ample research concerning the successful adoption of alkali activated binders in concrete, deigned for structural use and containing a wide variety of wastes such as (among many others) lead smelter slag [122], rubber tires [123], or coarse recycled aggregates [124].

\section{Conclusions}

The present document provides a detailed review of the current knowledge on the field of the utilization of wastes as aggregates in OPC for structural concrete. It presents an in-depth review of the strengths and weaknesses, according to the available literature, of the utilization of a wide range of wastes as aggregates for structural concretes. Bellow are the main conclusions of the research work performed:

- The utilization of low amounts of marble and granite wastes as aggregates in structural OPC concretes, especially when coupled with the use of proper water reducing agents. As to other mining and quarrying wastes, and especially for the case of materials originating from the extractive industry, their physical and geometric properties, as well as their high sulfides and heavy metal content, are particularly problematic and there is not yet sufficient scientific evidence to support the utilization of these wastes in OPC compositions.

- Due to their intrinsic pozzolanic nature and geometrical properties, by-products of coal-fired powerplants are prime candidates to be utilized as partial substitution of aggregates in concrete. Of these, fly ash is the material which possesses the best qualities for fine aggregate replacement. Nevertheless, it is a valuable by-product which may be more efficiently used as cement replacement. To a lesser extent, and for much lower replacement rates, bottom ash also demonstrates acceptable behavior as natural fine and coarse aggregate substitute. Finally, the limited use of boiler slag as coarse aggregate in concrete may be performed, if (once again) low replacement rates are utilized, and careful use of superplasticizers is implemented.

- Some metallurgy wastes tend to possess physical properties which are similar to those of natural aggregates and display pozzolanic behavior (especially evident in the case of blast furnace slags). Nevertheless, common issues originated by the use of these materials are heavy metal leaching (in the case of ACBFS or IFS), delayed setting (IFS), higher shrinkage, high active clay content (SFS), lower workability (except in the case of RGS and CS) and increased susceptibility to sulfates attack (most notoriously RGS) and lower freeze-thaw resistance 
(CFS). Notwithstanding, the replacement of natural aggregates for certain metallurgy wastes may benefit mechanical strength (RGS) and improve the microstructure of the concrete matrix (SFS).

- The reviewed literature does not support the use of thermoplastic waste as aggregate in concrete for structural applications as it tends to originate a higher level of open porosity, water absorption, increased entrapped air and lower workability. Additionally, the setting of concrete is also impacted by the hydrophobic nature of the plastics. Furthermore, the mechanical strength and durability properties of these wastes tend to deteriorate as plastic wastes are added and the compositions are apparently specially vulnerable to temperatures higher than $600^{\circ} \mathrm{C}$. On the other hand, finer PET and PVC particles may lead to the prevention of the occurrence of brittle failures and increase the abrasion resistance of concretes.

- As to glass wastes, the geometry of the grains substantially differs from that of natural aggregates, which may lead to a decrease in workability. Furthermore, while water absorption is generally upgraded by the addition of glass wastes, the mechanical strength, abrasion resistance, and elasticity modulus are usually slightly impacted by this practice. Moreover, concretes containing glass wastes are likely to experience higher ASR, although the presence of mineral admixtures such as fly ash can be effective in reducing this phenomenon. Finally, due to the lead leaching potential, specific measures have to be implemented when utilizing CRT wastes as aggregates in concrete (such as the use of a biopolymer solution for leaching encapsulation).

- Rubber wastes tend to possess lower density and higher water absorption than natural aggregates. Also, their shape can be significantly rounder in relation to the one displayed by aggregates of natural origin. As a consequence, when used as aggregates, these wastes tend to originate a density, water absorption and workability downgrade and an abrasion resistance upgrade in concrete compositions. Also, more significantly when finer fractions are used, the mechanical strength, elasticity modulus and shrinkage are also negatively affected by the presence of the referred waste.

- Low amounts of crushed mollusk shells may be used to replace fine natural aggregates, although only in non-structural concretes. Particle sizes inferior to $1 \mathrm{~mm}$ are to be avoided as the grains assume a highly flaky (needle) shape and the particle size distribution of this fraction is inappropriate. Also, the shells need a thorough water washing stage, mostly, to remove adhered sea salts. Furthermore, when compared to natural aggregates, the literature shows that the density of this waste is slightly lower and water absorption is higher. Additionally, the total salts content of the shells are likely to exceed the statutory limits for concrete aggregates. The partial substitution of natural aggregates for crushed seashells induces a general downgrade of the physical mechanical and durability properties of the concretes.

- Aggregates sourced from CDW may, according to the quality of the source material, be an adequate material for partially replacing natural aggregates in concrete compositions. From the four groups of wastes reviewed, the most promising material for use as aggregate in structural concrete is the one resulting from processing old structural concrete into a coarse granular material (RCA). The use of this waste, in low replacement rates, combined with measures to mitigate its disadvantages (namely the utilization of superplasticizers and mineral admixtures) has been proven to be effective in achieving a concrete suitable for the production of structural elements. As to the fine fraction of RCA, an also other CDW, these have been shown to downgrade the most important properties of con- cretes (most importantly strength and durability) and current knowledge does not support their use as an effective replacement for natural concretes in structural concretes.

- Alkali-activated concretes may constitute a superior alternative for the utilization of recycled wastes as concrete aggregates as they tend to possess higher mechanical strength (for the same water/binder ratio), also, the compressive strength of these materials is not so dependent on the optimization of the packing of the aggregates but rather on the characteristics of the binder-aggregates matrix, furthermore, $A A B$ concretes tend to display superior resistance to acid attack and lower susceptibility to ASR, and finally, demonstrate a better capacity for immobilizing hazardous materials.

The second part of this work, currently in preparation, concerns the subject of recycled aggregates utilization in alkali activated binder-based structural concretes.

\section{Declaration of Competing Interest}

The authors declare that they have no known competing financial interests or personal relationships that could have appeared to influence the work reported in this paper.

\section{Acknowledgement}

This research is sponsored by national funds through FCT - Fundação para a Ciência e Tecnologia, under the project SFRH/ $\mathrm{BD} / 111813 / 2015$.

\section{References}

[1] J.M. Allwood, J.M. Cullen, R.L. Milford, Options for achieving a 50\% cut in industrial carbon emissions by 2050, Environ. Sci. Technol. 44 (6) (2010) 1888-1894, https://doi.org/10.1021/es902909k.

[2] D.H. Meadows, D.L. Meadows, J. Randers, W.W. Berens III, The limits to growth, Potomac Associates - Universe Books (1972).

[3] D.H. Meadows, The history and clonclusions of The Limits to Growth, Syst. Dyn. Rev. 23 (2007) 191-197.

[4] European Commission, Roadmap to a Resource Efficient Europe. Communication from the Commision to the European Parliament, the Council and the European Economic and Social Committee and the Committee of the Regions, European Commission (2011) 1-26..

[5] F. Pacheco-Torgal, 1 - Introduction to advances in construction and demolition waste, in: F. Pacheco-Torgal, Y. Ding, F. Colangelo, R. Tuladhar, A.B.T.A. i. C. Koutamanis, D.W. Recycling (Eds.), Woodhead Publishing Series in Civil and Structural Engineering, Woodhead Publishing, 2020, pp. 1-10. https://doi.org/10.1016/B978-0-12-819055-5.00001-2. URL: http:// www.sciencedirect.com/science/article/pii/B9780128190555000012..

[6] S. Huysman, J. De Schaepmeester, K. Ragaert, J. Dewulf, S. De Meester, Performance indicators for a circular economy: a case study on postindustrial plastic waste, Resour. Conserv. Recycl. 120 (2017) 46-54, https:// doi.org/10.1016/j.resconrec.2017.01.013.

[7] P. Ghisellini, S. Ulgiati, 3 - Economic assessment of circular patterns and business models for reuse and recycling of construction and demolition waste, in: F. Pacheco-Torgal, Y. Ding, F. Colangelo, R. Tuladhar, A.B.T.A. i. C. Koutamanis, D.W. Recycling (Eds.), Woodhead Publishing Series in Civil and Structural Engineering, Woodhead Publishing, 2020, pp. 31-50.https://doi. org/10.1016/B978-0-12-819055-5.00003-6. URL: http:/ www.sciencedirect.com/science/article/pii/B9780128190555000036.

[8] Eurostat, Waste statistics, European Union (October) (2020) 1-12. URL: https://ec.europa.eu/eurostat/statistics-explained/index.php/Municipal_ waste statistics.

[9] M. Mpanza, E. Adam, R. Moolla, Dust deposition impacts at a liquidated gold mine village: Gauteng province in South Africa, Int. J. Environ. Res. Public Health 17 (14) (2020) 1-26, https://doi.org/10.3390/ijerph17144929.

[10] Department of Water Affairs and Forestry (DWAF), Waste Generation in South Africa; Water Quality Management Series: Pretoria, South Africa..

[11] Y. Benarchid, Y. Taha, R. Argane, M. Benzaazoua, Application of Quebec recycling guidelines to assess the use feasibility of waste rocks as construction aggregates, Resour. Policy 59 (January) (2018) 68-76, https:/| doi.org/10.1016/j.resourpol.2018.01.004.

[12] Y. Benarchid, Y. Taha, R. Argane, A. Tagnit-Hamou, M. Benzaazoua, Concrete containing low-sulphide waste rocks as fine and coarse aggregates: Preliminary assessment of materials, J. Clean. Prod. 221 (2019) 419-429, https://doi.org/10.1016/j.jclepro.2019.02.227. 
[13] P. Zhu, L.Y. Wang, D. Hong, G.R. Qian, M. Zhou, A study of making synthetic oxy-fluoride construction material using waste serpentine and kaolin mining tailings, Int. J. Miner. Process. 104-105 (2012) 31-36, https://doi.org/ 10.1016/j.minpro.2011.12.003.

[14] W. Xu, X. Wen, J. Wei, P. Xu, B. Zhang, Q. Yu, H. Ma, Feasibility of kaolin tailing sand to be as an environmentally friendly alternative to river sand in construction applications, J. Clean. Prod. 205 (2018) 1114-1126, https://doi. org/10.1016/j.jclepro.2018.09.119.

[15] R. Argane, M. El Adnani, M. Benzaazoua, H. Bouzahzah, A. Khalil, R. Hakkou, Y. Taha, Geochemical behavior and environmental risks related to the use of abandoned base-metal tailings as construction material in the upperMoulouya district, Morocco, Environ. Sci. Pollut. Res. 23 (1) (2016) 598611, https://doi.org/10.1007/s11356-015-5292-y.

[16] R. Argane, M. Benzaazoua, A. Bouamrane, R. Hakkou, Cement hydration and durability of low sulfide tailings-based renders: A case study in Moroccan constructions, Miner. Eng. 76 (2015) 97-108, https://doi.org/10.1016/j. mineng.2014.10.022

[17] S. Zhao, J. Fan, W. Sun, Utilization of iron ore tailings as fine aggregate in ultra-high performance concrete, Constr. Build. Mater. 50 (2014) 540-548, https://doi.org/10.1016/j.conbuildmat.2013.10.019.

[18] A. El Machi, S. Mabroum, Y. Taha, A. Tagnit-Hamou, M. Benzaazoua, R. Hakkou, Use of flint from phosphate mine waste rocks as an alternative aggregates for concrete, Constr. Build. Mater. 271 (2021), https://doi.org/ 10.1016/j.conbuildmat.2020.121886 121886.

[19] C.-q. Wang, X. yan Lin, M. He, D. Wang, S. lan Zhang, Environmental performance, mechanical and microstructure analysis of concrete containing oil-based drilling cuttings pyrolysis residues of shale gas, J. Hazard. Mater. 338 (2017) 410-427.https://doi.org/10.1016/j.jhazmat.2017.05.051.

[20] K. Vardhan, R. Siddique, S. Goyal, Strength, permeation and micro-structural characteristics of concrete incorporating waste marble, Constr. Build. Mater. 203 (2019) 45-55, https://doi.org/10.1016/j.conbuildmat.2019.01.079.

[21] V. Corinaldesi, G. Moriconi, T.R. Naik, Characterization of marble powder for its use in mortar and concrete, Constr. Build. Mater. 24 (1) (2010) 113-117, https://doi.org/10.1016/j.conbuildmat.2009.08.013.

[22] F. Gameiro, J.D. Brito, D.C. Silva, Durability performance of structural concrete containing fine aggregates from waste generated by marble quarrying industry, Eng. Struct. 59 (2014) 654-662, https://doi.org/10.1016/j. engstruct.2013.11.026.

[23] D. Silva, F. Gameiro, J. de Brito, Mechanical properties of structural concrete containing fine aggregates from waste generated by the marble quarrying industry, J. Mater. Civil Eng. 26(6).https://doi.org/10.1061/(ASCE)MT.19435533.0000948..

[24] A. André, J.D. Brito, A. Rosa, D. Pedro, Durability performance of concrete incorporating coarse aggregates from marble industry waste, J. Clean. Prod. 65 (2014) 389-396, https://doi.org/10.1016/j.jclepro.2013.09.037.

[25] P. Martins, J. De Brito, A. Rosa, D. Pedro, Mechanical performance of concrete with incorporation of coarse waste from the marble industry, Mater. Res. 17 (5) (2014) 1093-1101, https://doi.org/10.1590/1516-1439.210413.

[26] H. Hebhoub, H. Aoun, M. Belachia, H. Houari, E. Ghorbel, Use of waste marble aggregates in concrete, Constr. Build. Mater. 25 (3) (2011) 1167-1171, https://doi.org/10.1016/j.conbuildmat.2010.09.037.

[27] S. Singh, S. Khan, R. Khandelwal, A. Chugh, R. Nagar, Performance of sustainable concrete containing granite cutting waste, J. Clean. Prod. 119 (2016) 86-98, https://doi.org/10.1016/j.jclepro.2016.02.008.

[28] A. Jain, R. Gupta, S. Chaudhary, Performance of self-compacting concrete comprising granite cutting waste as fine aggregate, Constr. Build. Mater. 221 (2019) 539-552, https://doi.org/10.1016/j.conbuildmat.2019.06.104.

[29] M. Vijayalakshmi, A.S. Sekar, G. Ganesh Prabhu, Strength and durability properties of concrete made with granite industry waste, Constr. Build. Mater. 46 (2013) 1-7, https://doi.org/10.1016/j.conbuildmat.2013.04.018.

[30] M. Singh, R. Siddique, Strength properties and micro-structural properties of concrete containing coal bottom ash as partial replacement of fine aggregate, Constr. Build. Mater. 50 (2014) 246-256, https://doi.org/10.1016/ j.conbuildmat.2013.09.026

[31] CEN - European Committee for Standardization, EN 12620:2002+A1. Aggregates for concrete (2008)..

[32] R. Siddique, Effect of fine aggregate replacement with Class F fly ash on the abrasion resistance of concrete, Cem. Concr. Res. 33 (11) (2003) 1877-1881, https://doi.org/10.1016/S0008-8846(03)00212-6.

[33] R. Siddique, Effect of fine aggregate replacement with Class F fly ash on the mechanical properties of concrete, Cem. Concr. Res. 33 (4) (2003) 539-547, https://doi.org/10.1016/S0008-8846(02)01000-1.

[34] M. Tiwari, S.K. Sahu, R.C. Bhangare, P.Y. Ajmal, G.G. Pandit, Elemental characterization of coal, fly ash, and bottom ash using an energy dispersive Xray fluorescence technique, Appl. Radiat. Isot. 90 (2014) 53-57, https://doi. org/10.1016/j.apradiso.2014.03.002.

[35] M. Rafieizonooz, J. Mirza, M.R. Salim, M.W. Hussin, E. Khankhaje, Investigation of coal bottom ash and fly ash in concrete as replacement for sand and cement, Constr. Build. Mater. 116 (2016) 15-24, https://doi.org/ 10.1016/j.conbuildmat.2016.04.080.

[36] H.K. Kim, H.K. Lee, Use of power plant bottom ash as fine and coarse aggregates in high-strength concrete, Constr. Build. Mater. 25 (2) (2011) 1115-1122, https://doi.org/10.1016/j.conbuildmat.2010.06.065.

[37] A. Abdulmatin, W. Tangchirapat, C. Jaturapitakkul, An investigation of bottom ash as a pozzolanic material, Constr. Build. Mater. 186 (2018) 155-162, https://doi.org/10.1016/j.conbuildmat.2018.07.101.
[38] P. Smarzewski, D. Barnat-Hunek, W. Jezierski, The Possibility of Using Boiler Slag as Coarse Aggregate in High Strength Concrete, KSCE J. Civil Eng. 22 (5) (2018) 1816-1826, https://doi.org/10.1007/s12205-017-1377-0.

[39] P. Handley, V. Basuyau, Legal and Environmental Bottlenecks and Opportunities Slag-Based Products Valorisation, 6th International Slag Valorisation Symposium (2019) 249-261.

[40] R.K. Patra, B.B. Mukharjee, Influence of incorporation of granulated blast furnace slag as replacement of fine aggregate on properties of concrete, J Clean Prod 165 (2017) 468-476, https://doi.org/10.1016/j. jclepro.2017.07.125.

[41] M. Valcuende, F. Benito, C. Parra, I. Miñano, Shrinkage of self-compacting concrete made with blast furnace slag as fine aggregate, Constr. Build. Mater. 76 (2015) 1-9, https://doi.org/10.1016/j.conbuildmat.2014.11.029.

[42] A. Pribulová, P. Futáš, J. Petrík, M. Pokusová, M. Brzeziński, J. Jakubski, Comparison of cupola furnace and blast furnace slags with respect to possibilities of their utilization, Arch. Metall. Mater. 63 (4) (2018) 1865-1873, https://doi.org/10.24425/amm.2018.125117.

[43] J.D. Ríos, A. Vahí, C. Leiva, A.M. Martínez-De la Concha, H. Cifuentes, Analysis of the utilization of air-cooled blast furnace slag as industrial waste aggregates in self-compacting concrete, Sustainability (Switzerland) 11 (6). https://doi.org/10.3390/su11061702..

[44] T. Ozbakkaloglu, L. Gu, A. Fallah Pour, Normal- and high-strength concretes incorporating air-cooled blast furnace slag coarse aggregates: Effect of slag size and content on the behavior, Constr. Build. Mater. 126 (2016) 138-146, https://doi.org/10.1016/j.conbuildmat.2016.09.015.

[45] I. Janotka, Natural and Calcined Clayey Diatomite As Cement Replacement Materials: Microstructure and Pore Structure Study, Int. J. Res. Eng. Technol. 03 (25) (2014) 20-26, https://doi.org/10.15623/ijret.2014.0325004.

[46] J. Ladomerský, I. Janotka, E. Hroncová, I. Najdená, One-year properties of concrete with partial substitution of natural aggregate by cupola foundry slag, J. Clean. Prod. 131 (2016) 739-746, https://doi.org/10.1016/j. jclepro.2016.04.101.

[47] H. Motz, J. Geiseler, Products of steel slags an opportunity to save natural resources, Waste Manage. 21 (3) (2001) 285-293, https://doi.org/10.1016/ S0956-053X(00)00102-1.

[48] S.A. Zareei, F. Ameri, N. Bahrami, P. Shoaei, H.R. Moosaei, N. Salemi, Performance of sustainable high strength concrete with basic oxygen steelmaking (BOS)slag and nano-silica, J. Build. Eng. 25 (2019), https://doi.org/ 10.1016/j.jobe.2019.100791 100791.

[49] L. Coppola, A. Buoso, D. Coffetti, P. Kara, S. Lorenzi, Electric arc furnace granulated slag for sustainable concrete, Constr. Build. Mater. 123 (2016) 115-119, https://doi.org/10.1016/j.conbuildmat.2016.06.142.

[50] A.S. Brand, J.R. Roesler, Steel furnace slag aggregate expansion and hardened concrete properties, Cem. Concr. Compos. 60 (2015) 1-9, https://doi.org/ 10.1016/j.cemconcomp.2015.04.006.

[51] B. Erlin, D. Jana, Forces of hydration that can cause havoc in concrete, Concr. Int. 25 (11) (2003) 51-57.

[52] I. Papayianni, E. Anastasiou, Production of high-strength concrete using high volume of industrial by-products, Constr. Build. Mater. 24 (8) (2010) 14121417, https://doi.org/10.1016/j.conbuildmat.2010.01.016.

[53] M.H. Lai, J. Zou, B. Yao, J.C. Ho, X. Zhuang, Q. Wang, Improving mechanical behavior and microstructure of concrete by using BOF steel slag aggregate, Constr. Build. Mater. 277 (2021) 1-11, https://doi.org/10.1016/ j.conbuildmat.2021.122269.

[54] K.K. Sideris, C. Tassos, A. Chatzopoulos, P. Manita, Mechanical characteristics and durability of self compacting concretes produced with ladle furnace slag, Constr. Build. Mater. 170 (2018) 660-667, https://doi.org/10.1016/ j.conbuildmat.2018.03.091.

[55] A. Santamaría, J.J. González, M.M. Losáñez, M. Skaf, V. Ortega-López, The design of self-compacting structural mortar containing steelmaking slags as aggregate, Cem. Concr. Compos. 111 (April).https://doi.org/10.1016/j. cemconcomp.2020.103627..

[56] Y. Guney, Y.D. Sari, M. Yalcin, A. Tuncan, S. Donmez, Re-usage of waste foundry sand in high-strength concrete, Waste Manage. 30 (8-9) (2010) 1705-1713, https://doi.org/10.1016/j.wasman.2010.02.018.

[57] R.K. Sandhu, R. Siddique, Strength properties and microstructural analysis of self-compacting concrete incorporating waste foundry sand, Constr. Build. Mater. $225 \quad$ (2019) 371-383, https://doi.org/10.1016/ j.conbuildmat.2019.07.216.

[58] A. Parashar, P. Aggarwal, B. Saini, Y. Aggarwal, S. Bishnoi, Study on performance enhancement of self-compacting concrete incorporating waste foundry sand, Constr. Build. Mater. 251 (2020), https://doi.org/10.1016/ j.conbuildmat.2020.118875 118875.

[59] U. Mohammad, T. Quadir, K. Islam, A.H.M.M. Billah, M.S. Alam, Mechanical and durability properties of concrete using recycled granulated steel, Constr. Build. Mater. 123 (2016) 174-183, https://doi.org/10.1016/ j.conbuildmat.2016.06.139.

[60] R. Sharma, R.A. Khan, Durability assessment of self compacting concrete incorporating copper slag as fine aggregates, Constr. Build. Mater. 155 (2017) 617-629, https://doi.org/10.1016/j.conbuildmat.2017.08.074.

[61] K.S. Al-Jabri, A.H. Al-Saidy, R. Taha, Effect of copper slag as a fine aggregate on the properties of cement mortars and concrete, Constr. Build. Mater. 25 (2) (2011) 933-938, https://doi.org/10.1016/j.conbuildmat.2010.06.090.

[62] N. Gupta, R. Siddique, Strength and micro-structural properties of selfcompacting concrete incorporating copper slag, Constr. Build. Mater. 224 (2019) 894-908, https://doi.org/10.1016/j.conbuildmat.2019.07.105. 
[63] B. Tripathi, S. Chaudhary, Performance based evaluation of ISF slag as a substitute of natural sand in concrete, J. Clean. Prod. 112 (2016) 672-683, https://doi.org/10.1016/j.jclepro.2015.07.120.

[64] C. Morrison, R. Hooper, K. Lardner, The use of ferro-silicate slag from ISF zinc production as a sand replacement in concrete, Cem. Concr. Res. 33 (12) (2003) 2085-2089, https://doi.org/10.1016/S0008-8846(03)00234-5.

[65] C. Weeks, R.J. Hand, J.H. Sharp, Retardation of cement hydration caused by heavy metals present in ISF slag used as aggregate, Cem. Concr. Compos. 30 (10) (2008) 970-978, https://doi.org/10.1016/j.cemconcomp.2008.07.005.

[66] F. Iucolano, B. Liguori, D. Caputo, F. Colangelo, R. Cioffi, Recycled plastic aggregate in mortars composition: Effect on physical and mechanical properties, Mater. Des. 52 (2013) 916-922, https://doi.org/10.1016/ j.matdes.2013.06.025.

[67] F. Colangelo, R. Cioffi, B. Liguori, F. Iucolano, Recycled polyolefins waste as aggregates for lightweight concrete, Compos. Part B: Eng. 106 (2016) 234241, https://doi.org/10.1016/j.compositesb.2016.09.041.

[68] EN 206, Concrete - Specification, performance, production and conformity, British Standard (May) (2013) 30..

[69] N. Saikia, J. De Brito, Mechanical properties and abrasion behaviour of concrete containing shredded PET bottle waste as a partial substitution of natural aggregate, Constr. Build. Mater. 52 (2014) 236-244, https://doi.org/ 10.1016/j.conbuildmat.2013.11.049.

[70] R.V. Silva, J. De Brito, N. Saikia, Influence of curing conditions on the durability-related performance of concrete made with selected plastic waste aggregates, Cem. Concr. Compos. 35 (1) (2013) 23-31, https://doi.org/ 10.1016/j.cemconcomp.2012.08.017.

[71] A.O. Dawood, H. AL-Khazraji, R.S. Falih, Physical and mechanical properties of concrete containing PET wastes as a partial replacement for fine aggregates, Case Stud. Constr. Mater. 14 (2021) e00482.https://doi.org/10.1016/j.cscm. 2020.e00482.

[72] A.A. Mohammed, I.I. Mohammed, S.A. Mohammed, Some properties of concrete with plastic aggregate derived from shredded PVC sheets, Constr. Build. Mater. 201 (2019) 232-245, https://doi.org/10.1016/ j.conbuildmat.2018.12.145.

[73] S.C. Kou, G. Lee, C.S. Poon, W.L. Lai, Properties of lightweight aggregate concrete prepared with PVC granules derived from scraped PVC pipes, Waste Manage. 29 (2) (2009) 621-628, https://doi.org/10.1016/j. wasman.2008.06.014.

[74] M. Belmokaddem, A. Mahi, Y. Senhadji, B.Y. Pekmezci, Mechanical and physical properties and morphology of concrete containing plastic waste as aggregate, Constr. Build. Mater. 257 (2020), https://doi.org/10.1016/ j.conbuildmat.2020.119559 119559.

[75] Eurostat, No Title (2021). URL: https://appsso.eurostat.ec.europa.eu/ nui/submitViewTableAction.do..

[76] A. Saccani, M.C. Bignozzi, ASR expansion behavior of recycled glass fine aggregates in concrete, Cem. Concr. Res. 40 (4) (2010) 531-536, https://doi. org/10.1016/j.cemconres.2009.09.003.

[77] K. Zheng, Pozzolanic reaction of glass powder and its role in controlling alkali-silica reaction, Cem. Concr. Compos. 67 (2016) 30-38, https://doi.org/ 10.1016/j.cemconcomp.2015.12.008.

[78] L. Sun, X. Zhu, M. Kim, G. Zi, Alkali-silica reaction and strength of concrete with pretreated glass particles as fine aggregates, Constr. Build. Mater. 271 (2021), https://doi.org/10.1016/j.conbuildmat.2020.121809 121809.

[79] S. De Castro, J. De Brito, Evaluation of the durability of concrete made with crushed glass aggregates, J. Clean. Prod. 41 (2013) 7-14, https://doi.org/ 10.1016/j.jclepro.2012.09.021.

[80] N. Arabi, H. Meftah, H. Amara, O. Kebaïli, L. Berredjem, Valorization of recycled materials in development of self-compacting concrete: Mixing recycled concrete aggregates - Windshield waste glass aggregates, Constr. Build. Mater. 209 (2019) 364-376, https://doi.org/10.1016/ j.conbuildmat.2019.03.024

[81] S.C. Kou, C.S. Poon, Properties of self-compacting concrete prepared with recycled glass aggregate, Cem. Concr. Compos. 31 (2) (2009) 107-113, https://doi.org/10.1016/j.cemconcomp.2008.12.002.

[82] N. Tamanna, R. Tuladhar, N. Sivakugan, Performance of recycled waste glass sand as partial replacement of sand in concrete, Constr. Build. Mater. 239 (2020), https://doi.org/10.1016/j.conbuildmat.2019.117804 117804

[83] N. Omoding, L.S. Cunningham, G.F. Lane-Serff, Effect of using recycled waste glass coarse aggregates on the hydrodynamic abrasion resistance of concrete, Constr. Build. Mater. 268 (2021), https://doi.org/10.1016/ j.conbuildmat.2020.121177 121177

[84] Eurostat, No Title (2020). URL: https://ec.europa.eu/eurostat/databrowser/ view/ENV_WASELEE_custom_696324/default/table?lang=en.

[85] W. Song, D. Zou, T. Liu, J. Teng, L. Li, Effects of recycled CRT glass fine aggregate size and content on mechanical and damping properties of concrete, Constr. Build. Mater. 202 (2019) 332-340, https://doi.org/ 10.1016/j.conbuildmat.2019.01.033.

[86] D. Romero, J. James, R. Mora, C.D. Hays, Study on the mechanical and environmental properties of concrete containing cathode ray tube glass aggregate, Waste Manage. 33 (7) (2013) 1659-1666, https://doi.org/10.1016/ j.wasman.2013.03.018

[87] N.N. Pauzi, R. Hamid, M. Jamil, M.F. Zain, The effect of melted-spherical and crushed CRT funnel glass waste as coarse aggregates on concrete performance, J. Build. Eng. 35 (2021), https://doi.org/10.1016/j. jobe.2020.102035 102035 .
[88] M. Bravo, J. De Brito, Concrete made with used tyre aggregate: Durabilityrelated performance, Journal of Cleaner Production 25 (2012) 42-50, https:// doi.org/10.1016/j.jclepro.2011.11.066.

[89] F. Valadares, M. Bravo, J. De Brito, Concrete with used tire rubber aggregates: Mechanical performance, ACI Mater. J. 109 (3) (2012) 283-292.

[90] B.S. Thomas, R.C. Gupta, V.J. Panicker, Recycling of waste tire rubber as aggregate in concrete: Durability-related performance, J. Clean. Prod. 112 (2016) 504-513, https://doi.org/10.1016/j.jclepro.2015.08.046.

[91] H. Cuadrado-Rica, N. Sebaibi, M. Boutouil, B. Boudart, Properties of ordinary concretes incorporating crushed queen scallop shells, Mater. Struct. 49 (5) (2016) 1805-1816, https://doi.org/10.1617/s11527-015-0613-7.

[92] C. Varhen, S. Carrillo, G. Ruiz, Experimental investigation of Peruvian scallop used as fine aggregate in concrete, Constr. Build. Mater. 136 (2017) 533-540, https://doi.org/10.1016/j.conbuildmat.2017.01.067.

[93] ACI Committee 222, ACI 222R-01 Protection of Metals in Concrete Against Corrosion Reported by ACI Committee 222, Aci Committee Report (2001) 141.

[94] K.C. Panda, S. Behera, S. Jena, Effect of rice husk ash on mechanical properties of concrete containing crushed seashell as fine aggregate, Materials Today: Proceedings $32 \quad$ (2020) 838-843, https://doi.org/10.1016/ j.matpr.2020.04.049.

[95] C.C. Fan, R. Huang, H. Hwang, S.J. Chao, Properties of concrete incorporating fine recycled aggregates from crushed concrete wastes, Constr. Build. Mater. 112 (2016) 708-715, https://doi.org/10.1016/j.conbuildmat.2016.02.154.

[96] R.V. Silva, J. De Brito, R.K. Dhir, Properties and composition of recycled aggregates from construction and demolition waste suitable for concrete production, Constr. Build. Mater. 65 (2014) 201-217, https://doi.org/10.1016/ j.conbuildmat.2014.04.117.

[97] K.L. Scrivener, A.K. Crumbie, P. Laugesen, The interfacial transition zone (ITZ) between cement paste and aggregate in concrete, Interface Sci. 12 (4) (2004) 411-421, https://doi.org/10.1023/B:INTS.0000042339.92990.4c.

[98] M. Khedmati, Y.R. Kim, J.A. Turner, Investigation of the interphase between recycled aggregates and cementitious binding materials using integrated microstructural-nanomechanical-chemical characterization, Compos Part B: Eng 158 (July 2018) (2019) 218-229.https://doi.org/10.1016/j.compositesb. 2018.09.041.

[99] F. Cartuxo, J. De Brito, L. Evangelista, J.R. Jiménez, E.F. Ledesma, Increased durability of concrete made with fine recycled concrete aggregates using superplasticizers, Materials 9(2).https://doi.org/10.3390/ma9020098..

[100] D. Matias, J. De Brito, A. Rosa, D. Pedro, Mechanical properties of concrete produced with recycled coarse aggregates - influence of the use of superplasticizers, Constr. Build. Mater. 44 (2013) 101-109, https://doi.org/ 10.1016/j.conbuildmat.2013.03.011.

[101] W. Park, T. Noguchi, Influence of metal impurity on recycled aggregate concrete and inspection method for aluminum impurity, Constr. Build. Mater. 40 (2013) 1174-1183, https://doi.org/10.1016/j.conbuildmat.2012.03.009.

[102] S.C. Kou, C.S. Poon, Long-term mechanical and durability properties of recycled aggregate concrete prepared with the incorporation of fly ash, Cem. Concr. Compos. 37 (1) (2013) 12-19, https://doi.org/10.1016/j. cemconcomp.2012.12.011.

[103] R. Silva, J. de Brito, R. Dhir, Use of recycled aggregates arising from construction and demolition waste in new construction applications, J. Clean. Prod. 236 (2019), https://doi.org/10.1016/j.jclepro.2019.117629 117629.

[104] F. Debieb, S. Kenai, The use of coarse and fine crushed bricks as aggregate in concrete, Constr. Build. Mater. 22 (5) (2008) 886-893, https://doi.org/ 10.1016/j.conbuildmat.2006.12.013.

[105] J.S. González, F.L. Gayarre, C.L.C. Pérez, P.S. Ros, M.A. López, Influence of recycled brick aggregates on properties of structural concrete for manufacturing precast prestressed beams, Constr. Build. Mater. 149 (2017) (2017) 507-514, https://doi.org/10.1016/j.conbuildmat.2017.05.147.

[106] A. Halicka, P. Ogrodnik, B. Zegardlo, Using ceramic sanitary ware waste as concrete aggregate, Constr. Build. Mater. 48 (2013) 295-305, https://doi.org/ 10.1016/j.conbuildmat.2013.06.063.

[107] J. Dang, J. Zhao, Influence of waste clay bricks as fine aggregate on the mechanical and microstructural properties of concrete, Constr. Build. Mater. 228 (2019), https://doi.org/10.1016/j.conbuildmat.2019.116757 116757.

[108] B. Cantero, I.F. Sáez del Bosque, A. Matías, C. Medina, Statistically significant effects of mixed recycled aggregate on the physical-mechanical properties of structural concretes, Constr. Build. Mater. 185 (2018) 93-101, https://doi.org/ 10.1016/j.conbuildmat.2018.07.060.

[109] B. Mas, A. Cladera, J. Bestard, D. Muntaner, C.E. López, S. Piña, J. Prades, Concrete with mixed recycled aggregates: Influence of the type of cement, Constr. Build. Mater. 34 (2012) 430-441, https://doi.org/10.1016/ j.conbuildmat.2012.02.092.

[110] A. Juan-Valdés, D. Rodríguez-Robles, J. García-González, M.I. Sánchez de Rojas Gómez, M. Ignacio Guerra-Romero, N. De Belie, J.M. Morán-del Pozo, Mechanical and microstructural properties of recycled concretes mixed with ceramic recycled cement and secondary recycled aggregates. A viable option for future concrete, Constr. Build. Mater. 270.https://doi.org/10.1016/ j.conbuildmat.2020.121455.

[111] M.J. Chinchillas-Chinchillas, C.A. Rosas-Casarez, S.P. Arredondo-Rea, J.M. Gómez-Soberón, R. Corral-Higuera, SEM image analysis in permeable recycled concretes with silica fume. A quantitative comparison of porosity and the ITZ, Materials 12(13).https://doi.org/10.3390/ma12132201.. 
[112] C. Shi, Y. Li, J. Zhang, W. Li, L. Chong, Z. Xie, Performance enhancement of recycled concrete aggregate - a review, J. Clean. Prod. 112 (2016) 466-472, https://doi.org/10.1016/j.jclepro.2015.08.057.

[113] P. Velardo, I.F. Sáez del Bosque, A. Matías, M.I. Sánchez de Rojas, C. Medina, Properties of concretes bearing mixed recycled aggregate with polymermodified surfaces, J. Build. Eng. 38 (2020), https://doi.org/10.1016/j. jobe.2021.102211.

[114] LNEC, E 471-2009, Guia para utilização de agregados reciclados grossos em betões de ligantes hidráulicos 9 (2009) 8 .

[115] V. Corinaldesi, G. Moriconi, Influence of mineral additions on the performance of $100 \%$ recycled aggregate concrete, Constr. Build. Mater. 23 (8) (2009) 2869-2876, https://doi.org/10.1016/j.conbuildmat. 2009.02.004.

[116] M. Bravo, A. Santos Silva, J. De Brito, L. Evangelista, Mechanical Performance of Concrete Made with Aggregates from Construction and Demolition Waste Recycling Plants, J. Clean. Prod. 99 (2015) 59-74, https://doi.org/10.1017/ S1431927615015512.

[117] M. Bravo, J. De Brito, J. Pontes, L. Evangelista, Durability performance of concrete with recycled aggregates from construction and demolition waste plants, Constr. Build. Mater. 77 (2015) 357-369, https://doi.org/10.1016/ j.conbuildmat.2014.12.103.

[118] M. Bravo, J. de Brito, L. Evangelista, J. Pacheco, Durability and shrinkage of concrete with CDW as recycled aggregates: Benefits from superplasticizer's incorporation and influence of CDW composition, Constr. Build. Mater. 168 (2018) 818-830, https://doi.org/10.1016/j.conbuildmat.2018.02.176.

[119] C. Alexandridou, G.N. Angelopoulos, F.A. Coutelieris, Mechanical and durability performance of concrete produced with recycled aggregates from Greek construction and demolition waste plants, J. Clean. Prod. 176 (2018) 745-757, https://doi.org/10.1016/j.jclepro.2017.12.081.

[120] I.F. Sáez del Bosque, W. Zhu, T. Howind, A. Matías, M.I. Sánchez de Rojas, C. Medina, Properties of interfacial transition zones (ITZs) in concrete containing recycled mixed aggregate, Cem. Concr. Compos. 81 (2017) 2534, https://doi.org/10.1016/j.cemconcomp.2017.04.011.

[121] F. Pacheco-Torgal, Y. Ding, S. Miraldo, Z. Abdollahnejad, J.A. Labrincha, Are geopolymers more suitable than Portland cement to produce high volume recycled aggregates HPC?, Constr. Build. Mater. 36 (2012) 1048-1052, https://doi.org/10.1016/j.conbuildmat.2012.07.004.

[122] M. Albitar, M.S. Mohamed Ali, P. Visintin, Experimental study on fly ash and lead smelter slag-based geopolymer concrete columns, Constr. Build. Mater. 141 (2017) 104-112, https://doi.org/10.1016/j.conbuildmat.2017.03.014.

[123] A.M. Aly, M. El-Feky, M. Kohail, E.-S.A. Nasr, Performance of geopolymer concrete containing recycled rubber, Constr. Build. Mater. 207 (2019) 136144, https://doi.org/10.1016/j.conbuildmat.2019.02.121.

[124] F.U.A. Shaikh, Mechanical and durability properties of fly ash geopolymer concrete containing recycled coarse aggregates, Int. J. Sustain. Built Environ. 5 (2) (2016) 277-287, https://doi.org/10.1016/j.ijsbe.2016.05.009. 